\title{
Estrategia prospectiva para promover la educación ambiental en el quehacer docente
}

\section{Prospective Strategy to Promote Environmental Education in Teaching}

Estratégia prospectiva para promover a educação ambiental no ensino

Ramón Bedolla Solano

Universidad Autónoma de Guerrero, México rabedsol@hotmail.com https://orcid.org/0000-0001-6219-4953

*Juan José Bedolla Solano Tecnológico Nacional de México, Instituto Tecnológico de Acapulco, México jjosebedolla@hotmail.com https://orcid.org/0000-0001-6999-8823

*Adriana Miranda Esteban Universidad Autónoma de Guerrero, México mar86_05@hotmail.com https://orcid.org/0000-0003-4313-6146

*Autores de correspondencia 


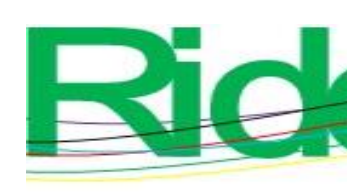

Revista Iberoamericana para la Investigación y el Desarrollo Educativo ISSN $2007-7467$

\section{Resumen}

Este estudio tuvo por objetivo promover competencias ambientales en docentes de tres programas educativos de nivel licenciatura de la Universidad Autónoma de Guerrero (UAGro): Sociología, Economía y Derecho; ello se dio a través de la implementación de un curso de educación ambiental no formal denominado La incorporación de la educación ambiental con enfoque transversal en el currículo, que se aplicó en septiembre-octubre de 2016. Es un estudio mixto, por ser un tema vinculado con la educación y por el hecho de que el investigador fue parte del objeto de estudio, se empleó el enfoque de la investigaciónacción. Se utilizó la rúbrica en la medición de aprendizajes y competencias adquiridas. La muestra fue por conveniencia: decidieron participar 20 profesores considerando los tres programas. En la evaluación de dicho curso se evidenció que los docentes lograron significativamente comprender saberes ambientales y el diseño metodológico de ambientalizar el trabajo que realizan, así como sus programas de unidades de aprendizaje y secuencias didácticas.

Palabras clave: currículo, competencias, docente, educación ambiental, estudiante, secuencia didáctica.

\section{Abstract}

The objective of this study was to promote environmental competencies in teachers of three undergraduate educational programs of the Universidad Autónoma de Guerrero (UAGro): Sociology, Economics and Law. This occurred through the implementation of a non-formal environmental education course called The incorporation of environmental education with a transversal approach in the curriculum, which was applied in September-October 2016. It's a mixed study, because it is a topic linked to education and because the researcher was part of the object of study, the action-research approach was used. A rubric was used to measure the learning and skills acquired. The sample was for convenience: 20 teachers considering the three programs decided to participate. In the evaluation of said course, it was evidenced that the teachers were able to significantly understand environmental knowledge and the methodological design of greening the work they do, as well as their learning unit programs and didactic sequences.

Keywords: curriculum, competences, teacher, environmental education, student, didactic sequence. 


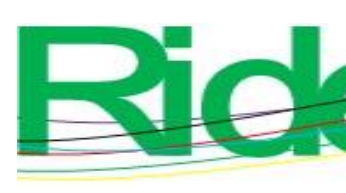

Revista Iberoamericana para la Investigación y el Desarrollo Educativo ISSN $2007-7467$

\section{Resumo}

O objetivo deste estudo foi promover competências ambientais em professores de três programas de ensino de graduação da Universidade Autônoma de Guerrero (UAGro): Sociologia, Economia e Direito; Isso ocorreu por meio da implantação de um curso não formal de educação ambiental denominado A incorporação da educação ambiental com abordagem transversal no currículo, que foi aplicado no período de setembro a outubro de 2016. É um estudo misto por se tratar de um tema vinculado à educação e pelo fato de o pesquisador fazia parte do objeto de estudo, foi utilizada a abordagem da pesquisa-ação. Uma rubrica foi usada para medir a aprendizagem e as habilidades adquiridas. A amostra foi por conveniência: 20 professores considerando os três programas decidiram participar. $\mathrm{Na}$ avaliação do referido curso, constatou-se que os professores foram capazes de compreender de forma significativa o conhecimento ambiental e o desenho metodológico de esverdeamento do trabalho que realizam, bem como seus programas de unidades de aprendizagem e sequências didáticas.

Palavras-chave: currículo, competências, professor, educação ambiental, aluno, sequência didática.

Fecha Recepción: Noviembre 2020

Fecha Aceptación: Mayo 2021

\section{Introducción}

En lo concerniente al trabajo docente, a la par de promover las competencias pedagógicas, se deben difundir las ambientales, y en conjunto implementar estrategias y técnicas didácticas cuya voz de mando sea la educación ambiental. El Modelo Educativo y Académico de la Universidad Autónoma de Guerrero [UAGro] 2004 ya planteaba la inclusión de dicho elemento. El Modelo Educativo 2013 lo fortaleció aún más, y añadió que la metodología de dicha dimensión fuera transversal. La dimensión ambiental, al ser vinculada al currículo nivel licenciatura en la UAGro, permea las competencias, el perfil de egreso, el mapa curricular, los programas de unidades de aprendizajes y las secuencias. Así, los docentes pueden formarse ambientalmente y adquirir competencias ambientales.

Las problemáticas ambientales se complican, afectan al planeta y a la sociedad. La universidad debe incluir la temática ambiental transversalmente en las carreras que oferta para así contribuir en la sustentabilidad que el mundo requiere. Quienes atienden la elaboración y reestructuración curricular deben establecer procedimientos para incluir el eje 


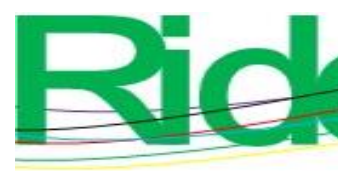

Revista Iberoamericana para la
Investigación y el Desarrollo Educativo
ISSN $2007-7467$

ambiental en un plan de estudio, en un programa de unidad de aprendizaje, en una secuencia didáctica. Además, ofrecer a los docentes estrategias para llevar a cabo la dimensión ambiental en las tareas que realizan. La fundamentación teórica y metodológica para poner en marcha la dimensión ambiental en el currículo universitario, específicamente en la UAGro, son los modelos educativos del 2004 y 2013. En estos documentos se plantea la sustentabilidad y las problemáticas ambientales como principios orientadores que deben ser atendidos.

La razón que ha llevado a incluir la dimensión ambiental en planes de estudios en las instituciones educativas es la problemática ambiental y socioambiental actual. La deforestación y la desertificación, el efecto invernadero, la contaminación de mares y océanos son algunas de las más alarmantes manifestaciones que estamos experimentado (Cortés, Aragonés, Amérigo y Sevillano, 2002, p. 279). De ahí la importancia de la educación. La educación para el desarrollo sostenible permite que cada ser humano adquiera los conocimientos, las competencias, las actitudes y los valores necesarios para forjar un futuro sostenible. Educar para el desarrollo sostenible significa incorporar los temas fundamentales de la sustentabilidad a la enseñanza y el aprendizaje, por ejemplo, el cambio climático, la reducción del riesgo de desastres, la biodiversidad, la reducción de la pobreza y el consumo sostenible (Organización de las Naciones Unidas para la Educación, la Ciencia y la Cultura [Unesco], s. f.).

Respecto a la sustentabilidad, se refiere a buscar la estabilidad o el equilibrio entre lo social, lo cultural y lo económico, teniendo siempre presente la salud del medio ambiente. Hay quienes utilizan de forma indistinta los términos sustentabilidad, sostenibilidad y desarrollo sustentable, pues, para fines prácticos, significan lo mismo (Quiroz, del Amo y Ramos, 2011). Para Hopwood, Mellor y O’Brien (2005), el concepto de desarrollo sostenible vincula fuertemente al medio ambiente y las cuestiones socioeconómicas

El método sugerido para integrar la dimensión ambiental en el currículo es la transversalidad. La transversalización es un proceso que recorre el currículo con contenidos que están presentes en todo el proceso educativo. Dichos contenidos son culturalmente relevantes y necesarios para la vida y la convivencia, ya que dan respuestas a problemas sociales y contribuyen a formar de manera especial el modelo de ciudadanos que demanda la sociedad. Son temas que no necesariamente tienen que conformar una asignatura en particular ni recibir un tratamiento especial dentro del currículo, sino que deben abordarse en todas las áreas que lo integran y en toda situación concreta de aprendizaje (Palos, citado en 


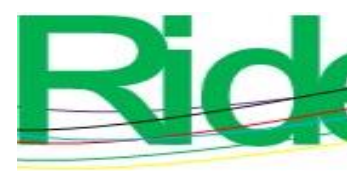

Revista Iberoamericana para la Investigación y el Desarrollo Educativo ISSN $2007-7467$

García, 2009). La transversalización del elemento ambiental en los planes de estudios debe considerar los componentes del eje medio ambiente (agua, aire, suelo y energía). Los contenidos del eje ambiental se proponen alrededor de cuatro tópicos: agua, aire, suelo y energía; y dentro de estos, el comportamiento humano en relación con dichos recursos, tales como importancia, disponibilidad, uso, problemáticas y alternativas (García, 2009). Así, los componentes del elemento medio ambiente se transformarán en conocimientos, habilidades, actitudes y valores o competencias (Aparicio, Rodríguez y Beltrán, 2014).

Uno de los sustentos pedagógicos de este estudio es el enfoque de competencias y el constructivismo sociocultural. Es necesario que los docentes promuevan competencias y conocimientos sobre el medio ambiente .

Tobón (citado en Casaña, 2015) asegura que las competencias son:

Procesos complejos de desempeño con idoneidad en determinados contextos, integrando diferentes saberes (saber ser, saber hacer, saber conocer y saber convivir), para realizar actividades y/o resolver problemas con sentido de reto, motivación, flexibilidad, creatividad, comprensión y emprendimiento, dentro de una perspectiva de procesamiento metacognitivo, mejoramiento continuo y compromiso ético, con la meta de contribuir al desarrollo personal, la construcción y afianzamiento del tejido social, la búsqueda continua del desarrollo económico-empresarial sostenible, y el cuidado y protección del ambiente y de las especies vivas (p. 22).

El constructivismo sociocultural tiene su origen en los trabajos de Lev S. Vygotsky y postula que el conocimiento se adquiere, según la ley de doble formación, primero a nivel intermental y posteriormente a nivel intrapsicológico; de esta manera, el factor social juega un papel determinante en la construcción del conocimiento (Serrano y Pons, 2011).

En el ámbito de la educación ambiental y de la educación para la sostenibilidad, la dimensión del futuro es un componente común a las diferentes corrientes o posiciones (Huckle, 1992; Junyent, Geli y Arbat, 2003; Hicks, 2002; Sterling, 1996; Tilbury, 1995; todos citados en Kong y Junyent, 2013). Esta idea destaca en el documento Década de la Educación para el Desarrollo Sostenible de la Unesco (citado en Kong y Junyent, 2013), donde se pone énfasis en las siguientes acciones de la educación: 1) es el agente primario de transformación hacia el desarrollo sostenible, incrementando las capacidades de la gente para transformar sus visiones de la sociedad en realidad; 2) fomenta valores, comportamiento y estilos de vida requeridos para un futuro sostenible; 3) es un proceso de aprendizaje de cómo tomar 


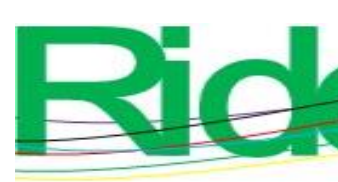

Revista Iberoamericana para la Investigación y el Desarrollo Educativo ISSN 2007 - 7467

decisiones que consideren el futuro de la equidad, economía y la ecología de todas las comunidades, y 4) construye la capacidad para el pensamiento orientado al futuro (Kong y Junyent, 2013).

En muchos casos, las universidades tienen como propósito responder a las necesidades del contexto con temáticas emergentes que deben ser incluidas en el currículo, como la de los derechos humanos, medio ambiente, entre otras, a través de ejes transversales; sin embargo, en algunos casos, los profesores no son actualizados o capacitados en conocer la metodología de intervenir ante ello, y así, aplicarlo en el trabajo que llevan a cabo. En este orden de ideas, es necesaria la capacitación a través de cursos, talleres o programas de educación no formales, como el que se llevó a cabo en este trabajo.

La impartición de cursos o programas diseñados y organizados para un grupo de personas implica capacitarlos, prepararlos, o bien, como se le denomina en el enfoque de competencias, promover conocimientos, habilidades, actitudes y valores para desempeñarse eficientemente en el trabajo o actividad que se lleva a cabo.

Este estudio se enmarca en una metodología mixta. Se consideraron técnicas cualitativas y cuantitativas. Respecto a la parte cualitativa, se adoptó un enfoque de la investigación-acción debido a que el investigador es parte del objeto de estudio. Asimismo, porque la investigación se desarrolló en un ambiente educativo con la promoción de competencias ambientales de profesores y se llegó a la descripción de los hechos encontrados, con la evaluación realizada. En el aspecto cuantitativo, cabe señalar que se utilizó una rúbrica que contempló una escala numérica para indicar resultados sobre la evaluación respectiva. Cabe mencionar también que dicho instrumento contempló indicar datos cualitativos.

Este estudio tuvo por objetivo promover competencias ambientales en docentes de tres programas educativos de nivel licenciatura: Sociología, Economía y Derecho; ello se dio a través de la implementación de un programa de educación ambiental no formal denominado La incorporación de la educación ambiental con enfoque transversal en el currículo, que se aplicó en septiembre-octubre de 2016. De acuerdo con el objetivo propuesto, se diseñó un método estratégico para incorporar el eje medio ambiente en el currículo (plan de estudio, programa de unidad de aprendizaje, secuencias didácticas, competencias). Se aplicó un programa de educación ambiental no formal dirigido a los docentes facilitadores de las unidades académicas muestra de este estudio (Economía, Sociología y Derecho) sobre la incorporación estratégica del eje medio ambiente en el currículo con orientaciones de la 


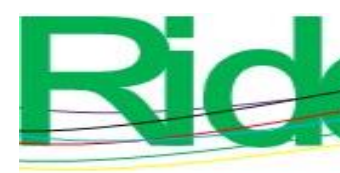

Revista Iberoamericana para la
Investigación y el Desarrollo Educativo
ISSN $2007-7467$

educación ambiental y perspectiva constructivista con el objetivo de generar competencias ambientales e introducir la educación ambiental transversalmente en el currículo. Se evaluaron las actividades realizadas en el curso para identificar cuáles fueron los aprendizajes adquiridos por los docentes.

De manera general, los resultados relacionados con la promoción de competencias ambientales con el curso implementado llevó a comprender que los docentes promovieron competencias ambientales sobre la importancia de incluir la dimensión ambiental en el currículo y específicamente en su quehacer docente.

En correspondencia con lo anterior, también se logró contar con un programa de educación ambiental no formal, su secuencia didáctica y el material didáctico (Guía metodológica para implementar transversalmente la educación ambiental).

Las promociones de competencias ambientales en los docentes hacen posible que estén capacitados para integrar la dimensión ambiental transversalmente en las tareas que realizan; por ejemplo, incluyendo esta temática en un plan de estudio, en un programa de unidad de aprendizaje, secuencia didáctica o en estrategias didácticas que utilizan para promover los aprendizajes de los estudiantes. Estas competencias, en algunos casos, no se hacen presente en los docentes o facilitadores debido a que no recibieron una capacitación por parte de la universidad o institución educativa que les requiere implementarlas.

\section{Método}

Este estudio fue mixto. Es decir: combina las miradas cuantitativas y cualitativas durante la fase empírica del estudio (Moscoso, 2017). A través del tiempo, el ser humano ha estado en la búsqueda constante de nuevos conocimientos; la investigación cuantitativa es una de las vías para obtenerlo, teniendo su soporte en la indagación a través de elementos cognitivos y de datos numéricos extraídos de la realidad, procesados estadísticamente para probar teorías (Del Canto y Silva, 2013). Un elemento característico en esta investigación que enmarca lo cuali-cuantitativo fue el empleo de la rúbrica que llevó a comprender las competencias y aprendizajes adquiridos. Las rúbricas o matrices de valoración brindan otro horizonte en relación con las calificaciones tradicionales que valoran el grado de aprendizaje del estudiante, expresadas en números o letras (Gatica y Uribarren, 2013). En cuanto a la metodología cualitativa, Osses (2006) plantea que la investigación cualitativa está orientada al estudio en profundidad de la compleja realidad social. Asimismo, el método seleccionado 


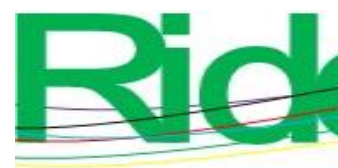

Revista Iberoamericana para la
Investigación y el Desarrollo Educativo
ISSN $2007-7467$

para este estudio fue la investigación-acción. Martínez (2006) establece que el método de investigación de acción es el único indicado cuando el investigador no solo quiere conocer una determinada realidad o un problema específico de un grupo, sino que desea también resolverlo. La investigación-acción es una opción metodológica cualitativa en educación (Colmenares, 2008).

\section{Población y muestra}

El Anuario Estadístico 2013-2014 de la UAGro (2014) expone que la planta de académicos entre el nivel medio superior (bachillerato y técnico universitario) y superior (licenciatura, maestría y doctorado) es de 2312 trabajadores. El número total de profesores que trabaja en el nivel licenciatura es de 1162, de los cuales 779 son hombres y 383 son mujeres. De acuerdo con el documento ya mencionado, esta universidad cuenta con 37 unidades académicas que atienden alrededor de 61 programas educativos de nivel licenciatura y tiene varias sedes en el estado de Guerrero; en Acapulco se ubican 16 unidades y entre ellas su planta de académicos asciende a 590. Siguiendo estos datos, la muestra quedó representada de la siguiente manera. La planta académica en la Escuela de Sociología es de 15, en la de Economía es de 15 y en la de Ciencias Sociales (Derecho) de 48. Así pues, el total de los docentes es 78. Se pretendió realizar este estudio con el total de docentes que contemplan dichos programas educativos, sin embargo, dentro de esta cantidad, se consideró solo a aquellos docentes que tuvieron el interés por participar en las actividades que se implementaron en esta etapa del proyecto. La metodología para seleccionar la muestra fue con base en el enfoque cualitativo, es decir, por conveniencia, considerando también los tiempos de la población objeto. En la tabla 1 se observa la muestra desglosada por programa educativo. 


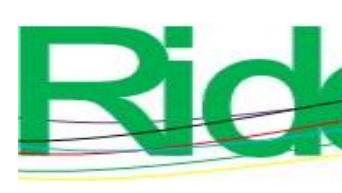

Revista Iberoamericana para la Investigación y el Desarrollo Educativo ISSN 2007 - 7467

Tabla 1.Muestra seleccionada

\begin{tabular}{|l|c|c|}
\hline Programa educativo & Planta académica & $\begin{array}{l}\text { Atendieron el programa y entregaron } \\
\text { actividades }\end{array}$ \\
\hline Sociología & 15 & 8 \\
\hline Economía & 15 & 9 \\
\hline Derecho & 48 & 20 \\
\hline Total & 78 & 3 \\
\hline
\end{tabular}

Fuente: Elaboración propia con base en el UAGro (2014)

Como se comentó en líneas anteriores, este estudio planteó como propósito promover competencias ambientales en docentes de tres programas educativos de nivel licenciatura (Sociología, Economía y Derecho). Y para lograrlo, se recurrió a las siguientes técnicas o procedimientos e instrumentos utilizados:

- $\quad$ Se diseñó y elaboró un método estratégico para incorporar el eje medio ambiente en el currículo (plan de estudio, programa de unidad de aprendizaje, secuencias didácticas, competencias).

- Se aplicó un programa de educación ambiental no formal dirigido a los docentes facilitadores de las unidades académicas muestra de este estudio sobre la incorporación estratégica del eje medio ambiente en el currículo con orientaciones de la educación ambiental y perspectiva constructivista con el objetivo de generar competencias ambientales e introducir la educación ambiental transversalmente en el currículo.

- Se evaluó, a través de una rúbrica cuali-cuantitativa, las actividades realizadas en el curso para identificar cuáles fueron los aprendizajes adquiridos por los docentes.

\section{Resultados}

\section{Diseño y elaboración del método estratégico para incorporar el eje medio ambiente en el currículo}

De noviembre del 2015 a julio de 2016 se trabajó en del diseño el programa de educación ambiental no formal. Se elaboró y organizó el programa, la secuencia didáctica y el material didáctico (Guía metodológica para implementar transversalmente la educación ambiental). Se recurrió al formato oficial para elaborar programas de unidades de aprendizaje de nivel licenciatura de la UAGro. Este formato contempla un esquema constructivista y de competencias para elaborar un programa educativo. Aunque se utilizó este formato, se 


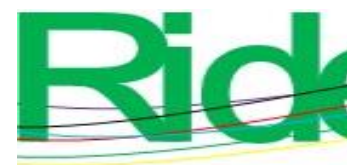

Revista Iberoamericana para la
Investigación y el Desarrollo Educativo
ISSN $2007-7467$

realizaron adaptaciones de tal manera que concordaran con el presente en relación con sus competencias. En lo que toca a la secuencia didáctica, fue la misma situación: su diseño y elaboración tomó en cuenta el formato oficial con que se elabora una planeación didáctica en el nivel licenciatura de la universidad. Cabe mencionar que las actividades que se planearon corresponden a lo estipulado en el programa y todas tuvieron que ver con la vinculación del medio ambiente en el currículo. La secuencia didáctica estableció la evaluación que se debía realizar para identificar las competencias o aprendizajes adquiridos. El programa del curso dio pie a la elaboración de un material didáctico que contribuye a formar las competencias establecidas en los docentes. El material didáctico se denominó Guía metodológica para implementar transversalmente la educación ambiental; contempló temas apegados al medio ambiente, la educación ambiental con enfoque del desarrollo y su aplicación transversal en el currículo. El objetivo de este material fue el de promover la dimensión ambiental o la educación ambiental en el plan de estudios, en los programas de unidades de aprendizaje, en la secuencia didáctica y en la formación del docente y de los estudiantes. Esta guía fue elaborada especialmente para los docentes que contribuyeron en el programa.

\section{Guía metodológica para implementar transversalmente la educación ambiental}

Este material contempló una portada, una introducción, en donde, de manera general, se expresó el contenido y los propósitos, contempló dos capítulos, uno en donde se fundamenta la implementación de la educación ambiental en el ámbito educativo y el segundo donde se establece la metodología para integrarlo. Tanto el primer capítulo como el segundo contemplan actividades que deben ser realizadas. Finalmente se incluye la bibliografía. Este material contempla un amplio estado del arte. La guía se diseñó con lineamientos pedagógicos constructivistas y de competencias, lo que garantiza alcanzar las competencias propuestas de acuerdo con los objetivos de la etapa dos del presente proyecto.

\section{Resultado de la aplicación del programa de educación ambiental no formal dirigido a los docentes facilitadores}

Entre los meses de septiembre-octubre de 2016, se implementó el programa de educación ambiental no formal, con el título "La incorporación de la educación ambiental con enfoque transversal en el currículo." Se registraron 38 docentes de los tres programas educativos (Sociología, Economía y Derecho). El material didáctico a utilizar fue entregado 


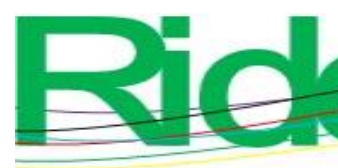

Revista Iberoamericana para la Investigación y el Desarrollo Educativo ISSN 2007 - 7467

a todos ellos. Sin embargo, solo 20 profesores atendieron el programa, presentaron actividades y evidencias de aprendizajes, tal como se observa en la tabla 2.

Tabla 2. Profesores que se registraron para participar en el programa "La incorporación de la educación ambiental con enfoque transversal en el currículo"

\begin{tabular}{|l|c|c|c|}
\hline Programa educativo & $\begin{array}{l}\text { Número de profesores } \\
\text { a quien se le entregó la } \\
\text { guía metodológica } \\
\text { entregadas }\end{array}$ & $\begin{array}{l}\text { Total de guías } \\
\text { programa y } \\
\text { entregaron } \\
\text { actividades }\end{array}$ \\
\hline Sociología & 8 & 8 & 8 \\
\hline Economía & 8 & 8 & 3 \\
\hline Derecho & 22 & 22 & 9 \\
\hline Total & 38 & 38 & 20 \\
\hline
\end{tabular}

Fuente: Elaboración propia

\section{Los docentes, el programa educativo y la secuencia didáctica}

Se presentó de manera no formal a los docentes el programa educativo y la secuencia didáctica, esto es, se acudió a sus cubículos, o donde estaban reunidos, y se les expuso a grandes rasgos de lo que trataba el curso; por supuesto, se hizo hincapié en la crisis ambiental y la necesidad urgente de emprender acciones para contrarrestrarla. Asimismo, se hizo alusión al modelo educativo de la UAGro, haciendo saber que sus principios y ejes transversales establecen la transversalización del tema medio ambiente en el currículo y, por ende, la integración de esta temática en las tareas que realiza el profesor. Se comentó también a los profesores que la modalidad de este programa era no formal, es decir, que el facilitador les daría un material donde realizarían las actividades: algunas de estas se realizarían de manera autodidacta y otras con el apoyo de un facilitador, en caso de ser necesario. El facilitador los contactaría personalmente o por medio de alguna red social. 


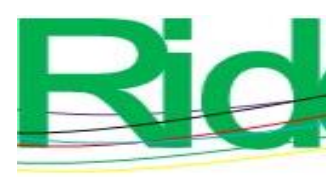

Revista Iberoamericana para la Investigación y el Desarrollo Educativo ISSN 2007 - 7467

\section{El programa educativo de educación ambiental no formal}

Estuvo constituido por dos partes. La primera parte del programa en cuestión se denominó Fundamentos y elementos de la transversalización y contó con alrededor de 11 actividades. La segunda parte se denominó Ambientaliza tu plan de estudio y contó con cinco actividades. Estas actividades se establecieron en la secuencia didáctica. El programa educativo ambiental no formal que se diseñó y la secuencia didáctica incluían conocimientos, habilidades y actitudes y valores a desarrollar (ver tabla 3 ).

Tabla 3.Competencia y elementos de competencia del programa educativo ambiental no formal

\begin{tabular}{|c|c|c|c|}
\hline \multirow[t]{2}{*}{ Competencia } & \multicolumn{3}{|c|}{ Elementos de competencia } \\
\hline & Conocimientos & Habilidades & Actitudes y valores \\
\hline $\begin{array}{l}\text { Promueve competencias } \\
\text { ambientales didáctico- } \\
\text { pedagógicas, a través de } \\
\text { la comprensión y } \\
\text { elaboración de } \\
\text { actividades que } \\
\text { propician aprendizajes } \\
\text { significativos para } \\
\text { transversalizar el } \\
\text { elemento medio } \\
\text { ambiente en el plan de } \\
\text { estudio, programa de } \\
\text { unidad de aprendizaje, } \\
\text { la secuencia didáctica y } \\
\text { las actividades que } \\
\text { realiza el profesor en la } \\
\text { UAGro con sentido } \\
\text { responsable. }\end{array}$ & $\begin{array}{l}\text { Comprende los } \\
\text { fundamentos y } \\
\text { elementos de } \\
\text { transversalización } \\
\text { ambiental en el } \\
\text { campo educativo y } \\
\text { en el currículo } \\
\text { universitario. }\end{array}$ & $\begin{array}{l}\text { Analiza los } \\
\text { fundamentos de la } \\
\text { educación ambiental } \\
\text { y, por ende, de su } \\
\text { implementación en el } \\
\text { currículo para contar } \\
\text { con el sustento } \\
\text { teórico y } \\
\text { metodológico. }\end{array}$ & $\begin{array}{l}\text { Genera } \\
\text { competencias que } \\
\text { contribuyen al } \\
\text { desarrollo } \\
\text { sustentable. }\end{array}$ \\
\hline
\end{tabular}

Fuente: Elaboración propia 


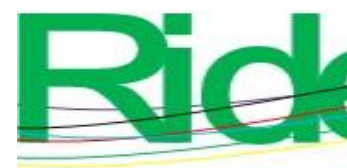

Revista Iberoamericana para la
Investigación y el Desarrollo Educativo
ISSN $2007-7467$

Los programas educativos que se diseñan y fundamentan bajo el enfoque de la educación basada en competencias explicitan una competencia y sus elementos de competencia (conocimientos, habilidades, actitudes y valores) para que el facilitador o docente que lo aplica tenga presente lo que se pretende lograr. Los temas vistos estuvieron apegados a la competencia y sus elementos de competencia.

En el siguiente apartado, que concierne a la evaluación de aprendizajes y competencias adquiridas, se complementa la aplicación del programa, debido a que se especifican las temáticas, actividades, evidencias y evaluación realizada.

\section{Resultados sobre la evaluación de las actividades realizadas en el curso para identificar los aprendizajes y competencias adquiridas por los docentes}

En cuanto a la evaluación de los aprendizajes de los docentes en el programa implementado, la entrega de la guía didáctica con ejercicios resueltos fue la evidencia de aprendizaje que permitió juzgar el nivel de comprensión sobre la temática ambiental y de competencias y aprendizajes en esta materia. Cada parte o temática del material contó con actividades (conceptuales, procedimentales y actitudinales) que el profesor debía resolver. En su mayoría, las actividades fueron ejercicios con preguntas abiertas (cuestionarios, identificación de conceptos relevantes, comprensión de la temática ambiental, actividades prácticas para implementar el elemento medio ambiente en el currículo, desarrollo de competencias y estrategias didácticas que los profesores debían de resolver). Para evaluar las respuestas, las actividades y, por ende, los aprendizajes, se diseñaron rúbricas. Los valores descritos en la rúbrica se establecieron de manera cuantitativa y cualitativa $(3=$ Mucho, $2=$ Parcialmente, $1=$ Poco, $0=$ Nada). Se analizaron las respuestas y el grado de aceptación de la siguiente forma:

- $\mathrm{MU}=3$, hace referencia al total de profesores que contestaron o realizaron un cuestionario o ejercicio acertadamente.

- $\quad \mathrm{PA}=2$, refiere al total de profesores que contestaron un cuestionario o actividades con pocas deficiencias.

- $\quad \mathrm{PO}=1$, hace referencia a los profesores que presentaron muchas deficiencias en las respuestas que dieron a los cuestionarios o actividades que presentaron. 

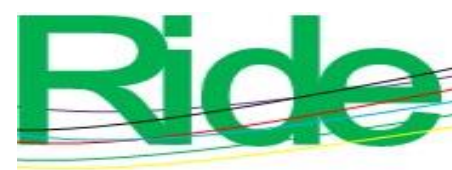

Revista Iberoamericana para la Investigación y el Desarrollo Educativo ISSN 2007 - 7467

- $\quad \mathrm{NA}=0$, se refiere a los docentes que definitivamente no contestaron o presentaron errores significativos en las respuestas o actividades.

De esta manera, se pudo conocer el nivel de conocimientos previos y competencias o aprendizaje obtenidos de los docentes que componen la muestra de este estudio. Como ya se comentó, la guía o material didáctico que se empleó en el programa y que fue la evidencia significativa de este programa estuvo constituida por dos partes ("Fundamentos y elementos de la transversalización" y “Ambientaliza tu plan de estudio"). En total, fueron 14 rúbricas o tablas que se emplearon para presentar los resultados. La última actividad de la segunda parte se evaluó a través de un análisis. En las siguientes líneas se exponen las rúbricas y los resultados de cada una de las actividades.

\section{Primera actividad}

En esta primera actividad del material didáctico se realizó una evaluación diagnóstica sobre la inclusión del elemento medio ambiente en el currículo, en el programa de unidad de aprendizaje, la secuencia didáctica y las competencias ambientales del docente. Fue un cuestionario abierto que se aplicó con el propósito de conocer información del docente sobre la incorporación del elemento ambiental en el currículo y sobre las competencias ambientales que él o ella posee y que son fundamentales para generar competencias de esta índole en los estudiantes, como se presenta en la tabla 4. 


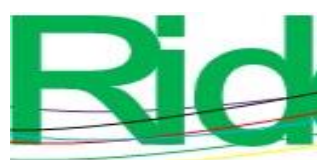

e

Revista Iberoamericana para la

Investigación y el Desarrollo Educativo

ISSN $2007-7467$

Tabla 4. Resultado de la evaluación diagnóstica sobre la inclusión del elemento medio ambiente en el currículo, en el programa de unidad de aprendizaje, la secuencia didáctica y las competencias ambientales del docente

Objetivo de la entrevista: comprender si los docentes del programa educativo de Sociología, Economía y Derecho implementan el elemento ambiental transversalmente.

Las claves: $\mathrm{MU}=$ Mucho (3), PA = Parcialmente (2), PO = Poco (1), NA = Nada (0).

\begin{tabular}{|c|c|c|c|c|c|c|c|c|c|c|c|c|}
\hline \multirow[t]{3}{*}{ Preguntas } & \multicolumn{12}{|c|}{ Programas educativos } \\
\hline & \multicolumn{4}{|c|}{ Sociología } & \multicolumn{4}{|c|}{ Economía } & \multicolumn{4}{|c|}{ Derecho } \\
\hline & $\begin{array}{l}\text { MU } \\
3\end{array}$ & $\begin{array}{l}\text { PA } \\
2\end{array}$ & $\begin{array}{l}\text { PO } \\
1\end{array}$ & $\begin{array}{l}\text { NA } \\
0\end{array}$ & $\begin{array}{l}\text { MU } \\
3\end{array}$ & $\begin{array}{l}\text { PA } \\
2\end{array}$ & $\begin{array}{l}\text { PO } \\
1\end{array}$ & $\begin{array}{l}\text { NA } \\
0\end{array}$ & $\begin{array}{l}\text { MU } \\
3\end{array}$ & $\begin{array}{l}\text { PA } \\
2\end{array}$ & $\begin{array}{l}\text { PO } \\
1\end{array}$ & $\begin{array}{l}\text { NA } \\
0\end{array}$ \\
\hline $\begin{array}{l}\text { ¿Sabe cuáles son } \\
\text { las problemáticas } \\
\text { que afectan a } \\
\text { nuestra sociedad y } \\
\text { al mundo entero? }\end{array}$ & $\begin{array}{l}\text { XX } \\
\text { XX } \\
\text { X }\end{array}$ & $X$ & & $\begin{array}{l}X \\
X\end{array}$ & XX & & $X$ & & $\begin{array}{l}X X \\
X X \\
X X \\
X\end{array}$ & & XX & \\
\hline $\begin{array}{l}\text { ¿Sabe cuál es el } \\
\text { procedimiento para } \\
\text { que una } \\
\text { problemática pueda } \\
\text { ser considerada en } \\
\text { el currículo } \\
\text { universitario? } \\
\text { Comente por favor. }\end{array}$ & $\mathrm{XX}$ & & $\mathrm{XX}$ & $\begin{array}{l}X X \\
X \\
X\end{array}$ & $\mathrm{XX}$ & & & $\mathrm{X}$ & $\mathrm{XX}$ & $\mathrm{XX}$ & XX & $\begin{array}{l}X X \\
X\end{array}$ \\
\hline $\begin{array}{l}\text { ¿El elemento } \\
\text { medio ambiente } \\
\text { está incluido en el } \\
\text { currículo o plan de } \\
\text { estudio en el que } \\
\text { labora? Diga cómo. }\end{array}$ & $\mathrm{X}$ & & & $\begin{array}{l}\text { XX } \\
\text { XX } \\
X \\
X X\end{array}$ & & & $\mathrm{XX}$ & $\mathrm{X}$ & & $\begin{array}{l}X X \\
X X \\
X\end{array}$ & $\mathrm{XX}$ & $\mathrm{XX}$ \\
\hline
\end{tabular}




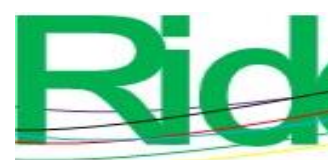

e

Revista Iberoamericana para la Investigación y el Desarrollo Educativo ISSN 2007 - 7467

Después de haber leído y comprendido esta temática, los docentes contestaron un cuestionario con preguntas abiertas relacionadas con los objetivos de dicho punto. Los resultados se observan en la tabla 5 .

Tabla 5.Resultado de la comprensión del elemento ambiente con enfoque transversal de acuerdo con el modelo educativo de la UAGro

Objetivo del cuestionario: comprende que el modelo educativo de la UAGro sugiere la implementación del elemento medio ambiente en el currículo.

Las claves: $\mathrm{MU}=$ Mucho (3), PA = Parcialmente (2), PO = Poco (1), NA = Nada (0).

\begin{tabular}{|c|c|c|c|c|c|c|c|c|c|c|c|c|}
\hline \multirow[t]{3}{*}{ Preguntas } & \multicolumn{12}{|c|}{ Programas educativos } \\
\hline & \multicolumn{4}{|c|}{ Sociología } & \multicolumn{4}{|c|}{ Economía } & \multicolumn{4}{|c|}{ Derecho } \\
\hline & $\begin{array}{l}\text { MU } \\
3\end{array}$ & $\begin{array}{l}\text { PA } \\
2\end{array}$ & $\begin{array}{l}\text { PO } \\
1\end{array}$ & $\begin{array}{l}\text { NA } \\
0\end{array}$ & $\begin{array}{l}\text { MU } \\
3\end{array}$ & $\begin{array}{l}\text { PA } \\
2\end{array}$ & $\begin{array}{l}\text { PO } \\
1\end{array}$ & $\begin{array}{l}\text { NA } \\
0\end{array}$ & $\begin{array}{l}\text { MU } \\
3\end{array}$ & $\begin{array}{l}\text { PA } \\
2\end{array}$ & $\begin{array}{l}\text { PO } \\
1\end{array}$ & $\begin{array}{l}\text { NA } \\
0\end{array}$ \\
\hline $\begin{array}{l}\text { ¿Qué documentos } \\
\text { en la UAGro } \\
\text { establecen que el } \\
\text { elemento medio } \\
\text { ambiente tiene que } \\
\text { ser implementado } \\
\text { como tema } \\
\text { transversal en el } \\
\text { currículo? }\end{array}$ & $\begin{array}{l}\text { XX } \\
\text { XX } \\
\text { XX }\end{array}$ & & & $\mathrm{XX}$ & $\mathrm{XX}$ & & & $\mathrm{X}$ & $\begin{array}{l}\text { XX } \\
\text { XX } \\
\text { XX } \\
\text { XX } \\
X\end{array}$ & & & \\
\hline $\begin{array}{l}\text { ¿Considera urgente } \\
\text { la inclusión del } \\
\text { elemento medio } \\
\text { ambiente en el plan } \\
\text { de estudio de la } \\
\text { institución donde } \\
\text { labora? ¿Por qué? }\end{array}$ & $\begin{array}{l}\mathrm{XX} \\
\mathrm{XX} \\
\mathrm{XX} \\
\mathrm{X}\end{array}$ & & $\mathrm{X}$ & & $\mathrm{XX}$ & & $\mathrm{X}$ & & $\begin{array}{l}\text { XX } \\
\text { XX } \\
\text { XX } \\
\text { XX }\end{array}$ & $\mathrm{X}$ & & \\
\hline $\begin{array}{l}\text { De acuerdo con el } \\
\text { modelo educativo, } \\
\text { ¿cómo se }\end{array}$ & $\begin{array}{l}\text { XX } \\
\text { XX }\end{array}$ & & & & $\mathrm{XX}$ & & & $\mathrm{X}$ & $\begin{array}{l}\text { XX } \\
\text { XX }\end{array}$ & $\mathrm{XX}$ & & \\
\hline
\end{tabular}




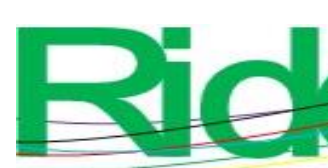

\begin{tabular}{|l|l|l|l|l|l|l|l|l|l|l|l|l|}
\hline $\begin{array}{l}\text { comprende la } \\
\text { incorporación del } \\
\text { tema ambiental en } \\
\text { el currículo? }\end{array}$ & $\mathrm{XX}$ \\
\hline $\begin{array}{l}\text { ¿Considera que la } \\
\text { implementación del } \\
\text { tema axbiental en } \\
\text { el currículo } \\
\text { coadyuva en la } \\
\text { sustentabilidad que } \\
\text { nuestra región y } \\
\text { país necesita? ¿Por } \\
\text { qué? }\end{array}$
\end{tabular}

Fuente: Elaboración propia

El valor MU = 3 fue significativo en los tres programas; ello indica que son varios docentes que saben que el modelo educativo de la UAGro establece la integración del eje medio ambiente como tema transversal y que influye en la sustentabilidad.

\section{Tercera actividad}

Los docentes dieron lectura al punto "Problemáticas ambientales". Luego, respondieron un cuestionario con preguntas abiertas con el propósito de identificar la percepción que tienen los docentes acerca de la crisis ambiental. Los resultados se exponen en la tabla 6. 


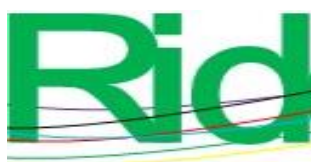

Tabla 6. Resultado de la percepción de la percepción sobre la crisis ambiental

\begin{tabular}{|c|c|c|c|c|c|c|c|c|c|c|c|c|}
\hline \multicolumn{13}{|c|}{$\begin{array}{l}\text { Objetivo del cuestionario: percibe la problemática ambiental para actuar responsablemente en el } \\
\text { cuidado del medio. }\end{array}$} \\
\hline \multicolumn{13}{|c|}{ Las claves: $\mathrm{MU}=$ Mucho (3), PA = Parcialmente (2), PO = Poco (1), NA = Nada (0). } \\
\hline \multirow[t]{3}{*}{ Preguntas } & \multicolumn{12}{|c|}{ Programas educativos } \\
\hline & \multicolumn{4}{|c|}{ Sociología } & \multicolumn{4}{|c|}{ Economía } & \multicolumn{4}{|c|}{ Derecho } \\
\hline & $\begin{array}{l}\text { MU } \\
3\end{array}$ & $\begin{array}{l}\text { PA } \\
2\end{array}$ & $\begin{array}{l}\text { PO } \\
1\end{array}$ & $\begin{array}{l}\text { NA } \\
0\end{array}$ & $\begin{array}{l}\text { MU } \\
3\end{array}$ & $\begin{array}{l}\mathrm{PA} \\
2\end{array}$ & $\begin{array}{l}\text { PO } \\
1\end{array}$ & $\begin{array}{l}\text { NA } \\
0\end{array}$ & $\begin{array}{l}\text { MU } \\
3\end{array}$ & $\begin{array}{l}\text { PA } \\
2\end{array}$ & $\begin{array}{l}\text { PO } \\
1\end{array}$ & $\begin{array}{l}\text { NA } \\
0\end{array}$ \\
\hline $\begin{array}{l}\text { ¿Percibe de manera } \\
\text { preocupante la } \\
\text { problemática } \\
\text { ambiental? ¿Por } \\
\text { qué? }\end{array}$ & $\begin{array}{l}X X \\
X X \\
X\end{array}$ & $X X$ & $X$ & & XX & & $X$ & & $\begin{array}{l}X X \\
X X \\
X\end{array}$ & $\begin{array}{l}X X \\
X\end{array}$ & & \\
\hline $\begin{array}{l}\text { De acuerdo con lo } \\
\text { que se expone, } \\
\text { ¿quién es el } \\
\text { principal } \\
\text { responsable de las } \\
\text { problemáticas } \\
\text { ambientales? }\end{array}$ & $\begin{array}{l}\text { XX } \\
\text { XX } \\
X X \\
X X\end{array}$ & & & & $\begin{array}{l}X X \\
X\end{array}$ & & & & $\begin{array}{l}X X \\
X X \\
X X \\
X X \\
X\end{array}$ & & & \\
\hline $\begin{array}{l}\text { ¿Considera usted } \\
\text { que un problema } \\
\text { ambiental que } \\
\text { sucede en una } \\
\text { zona, o en un país, } \\
\text { se refleja en otras } \\
\text { zonas o países? } \\
\text { ¿Por qué? }\end{array}$ & $\begin{array}{l}\text { XX } \\
\text { XX } \\
\text { XX }\end{array}$ & & $X X$ & & $\mathrm{XX}$ & & $\mathrm{X}$ & & $\begin{array}{l}\text { XX } \\
\text { XX } \\
\text { XX } \\
X X \\
X\end{array}$ & & & \\
\hline $\begin{array}{l}\text { ¿Considera usted } \\
\text { que la problemática } \\
\text { ambiental impacta }\end{array}$ & $\begin{array}{l}X X \\
X X \\
X\end{array}$ & $\begin{array}{l}X X \\
X\end{array}$ & & & XX & & $\mathrm{X}$ & & $\begin{array}{l}\mathrm{XX} \\
\mathrm{XX} \\
\mathrm{XX}\end{array}$ & & & \\
\hline
\end{tabular}




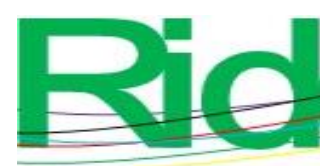

\begin{tabular}{|c|c|c|c|c|c|c|c|c|}
\hline $\begin{array}{l}\text { educación } \\
\text { ambiental después } \\
\text { de los } 90 \text { con el } \\
\text { enfoque del } \\
\text { desarrollo } \\
\text { sostenible? }\end{array}$ & $\begin{array}{l}\text { XX } \\
\text { X }\end{array}$ & & & & & $\begin{array}{l}\text { XX } \\
\text { XX }\end{array}$ & & \\
\hline $\begin{array}{l}\text { ¿Se sugiere que la } \\
\text { educación } \\
\text { ambiental sea } \\
\text { integrada en el } \\
\text { currículo como una } \\
\text { disciplina o como } \\
\text { un proceso? } \\
\text { Explique. }\end{array}$ & $\begin{array}{l}\text { XX } \\
\text { XX } \\
\text { XX }\end{array}$ & XX & XX & X & & $\begin{array}{l}\text { XX } \\
\text { XX } \\
\text { XX }\end{array}$ & $X$ & $X$ \\
\hline $\begin{array}{l}\text { ¿Cuál es el enfoque } \\
\text { que debe } \\
\text { implementar el } \\
\text { proceso de la } \\
\text { educación } \\
\text { ambiental en el } \\
\text { currículo? }\end{array}$ & $\begin{array}{l}\text { XX } \\
\text { XX } \\
\text { XX }\end{array}$ & XX & XX & & X & $\begin{array}{l}\text { XX } \\
\text { XX } \\
\text { XX } \\
\text { X }\end{array}$ & $X$ & $X$ \\
\hline
\end{tabular}

Fuente: Elaboración propia

En la tabla 7 es posible observar que las respuestas se alinearon al valor $\mathrm{MU}=3$, lo que indica que casi la mayoría de los profesores de los tres programas educativos comprende que la educación ambiental en el currículo debe insertarse con un enfoque de desarrollo sostenible.

\section{Quinta actividad}

Los docentes dieron lectura y comprendieron el punto "Desarrollo sustentable. Principios generales del Modelo Educativo 2013 de la UAGro (sustentabilidad)". Aquí también respondieron un cuestionario con preguntas abiertas. El propósito de dicho 


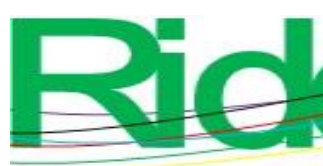

Revista Iberoamericana para la Investigación y el Desarrollo Educativo ISSN 2007 - 7467

instrumento fue analizar el concepto de desarrollo sustentable y sus sinónimos. Los resultados se detallan en la tabla 8 .

Tabla 8. Resultado del análisis del desarrollo sustentable y los principios generales del Modelo Educativo 2013 UAGro (sustentabilidad)

Objetivo del cuestionario: analiza el desarrollo sustentable y su inclusión como principio general del modelo educativo de la UAGro.

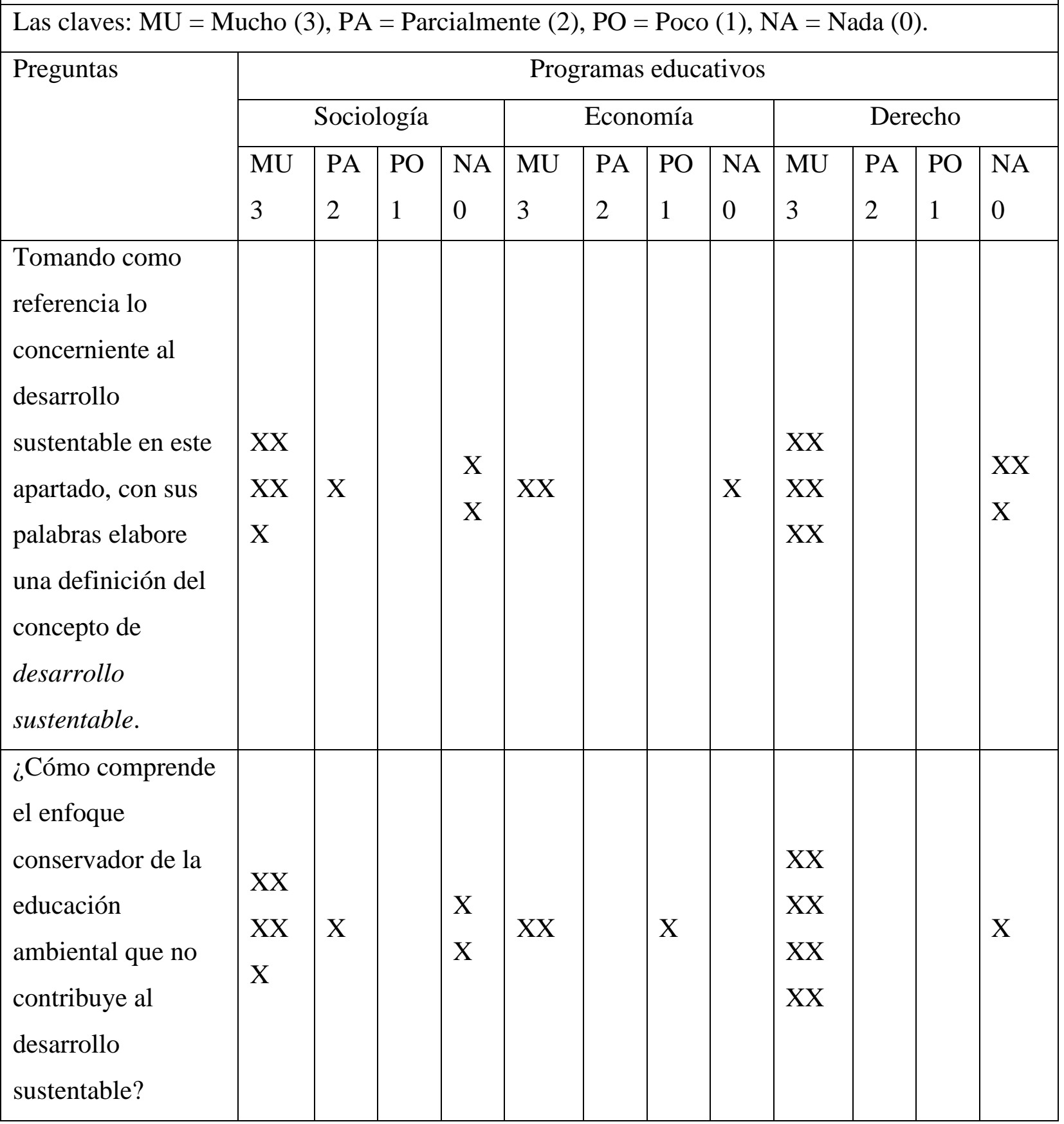




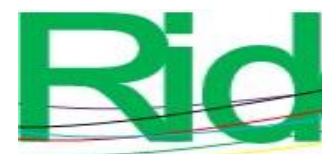

Revista Iberoamericana para la Investigación y el Desarrollo Educativo ISSN 2007 - 7467

\begin{tabular}{|l|l|l|l|l|l|l|l|l|l|l|l|l|}
\hline ¿Cómo comprende & & & & & & & & & & & & \\
el enfoque de la & & & & & & & & & $\mathrm{XX}$ & & & \\
educación & $\mathrm{XX}$ & & & $\mathrm{X}$ & & & & & $\mathrm{XX}$ & & & \\
ambiental que & $\mathrm{XX}$ & $\mathrm{X}$ & & $\mathrm{X}$ & $\mathrm{XX}$ & & $\mathrm{X}$ & & $\mathrm{XX}$ & $\mathrm{X}$ & & $\mathrm{X}$ \\
contribuye al & $\mathrm{X}$ & & & & & & & & $\mathrm{X}$ & & \\
desarrollo & & & & & & & & & & & & \\
sustentable? & & & & & & & & & & & & \\
\hline
\end{tabular}

Fuente: Elaboración propia

En este apartado, la mayoría de las respuestas van orientadas a $\mathrm{MU}=3$, lo que indica que los profesores de los tres programas educativos comprendieron el término desarrollo sustentable y la importancia de ser incluido como principio del modelo educativo de la UAGro, si bien hay profesores que presentaron deficiencias en su comprensión.

\section{Sexta actividad}

Los docentes dieron lectura al material del punto "La educación ambiental como tema transversal en el currículo". Aunado a ello, respondieron un cuestionario. El propósito de dicho instrumento fue analizar y comprender el enfoque de la educación ambiental en el currículo. (Ver tabla 9). 


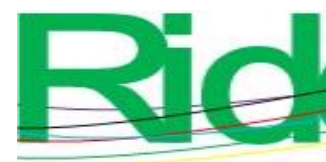

Tabla 9. Resultado del análisis y comprensión la educación ambiental como tema transversal en el currículo

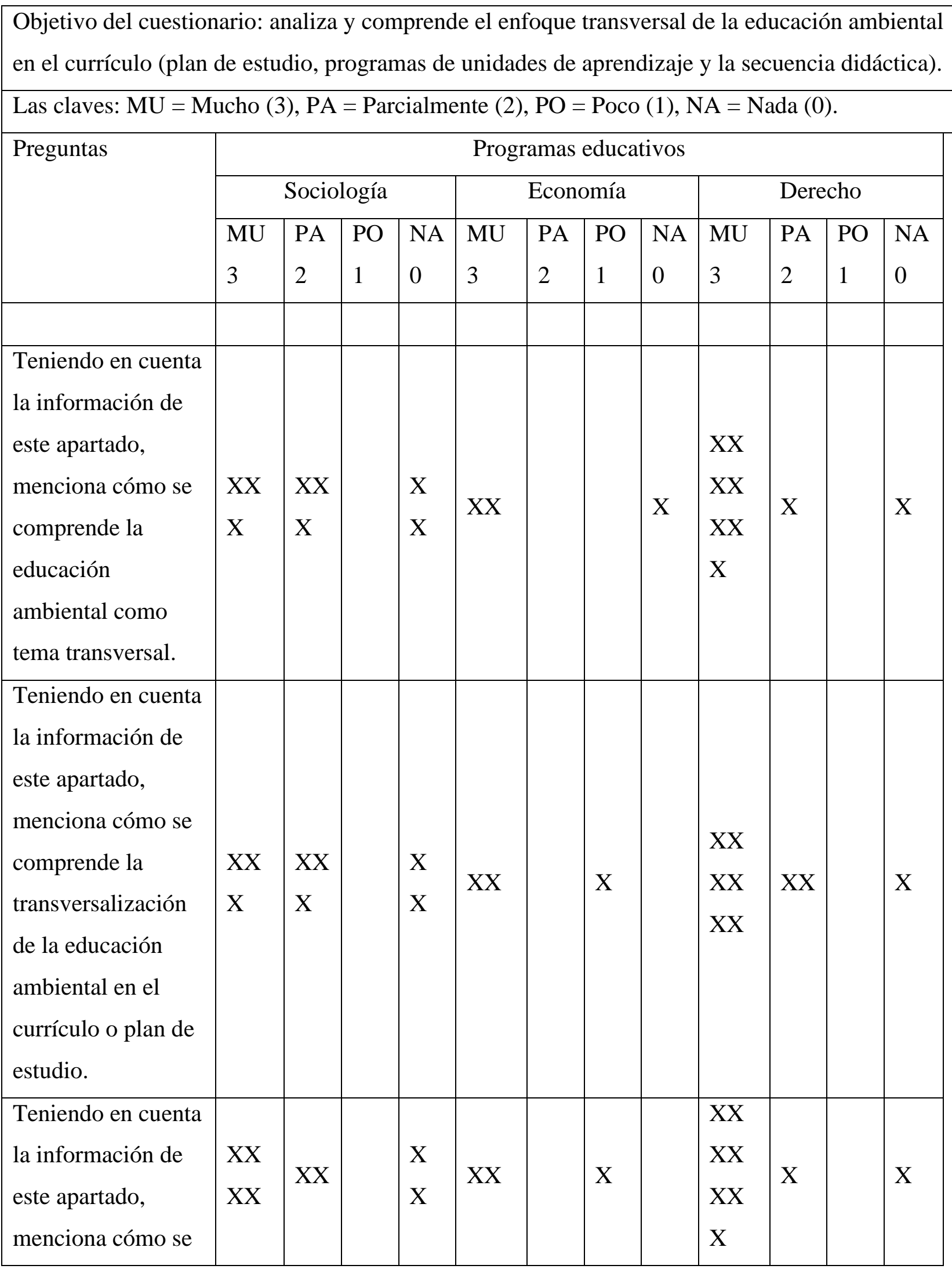




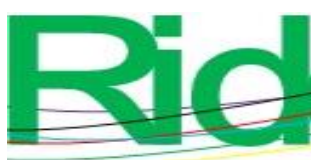

Tabla 10.Resultado de comprensión de competencias del profesor de la UAGro y competencias ambientales

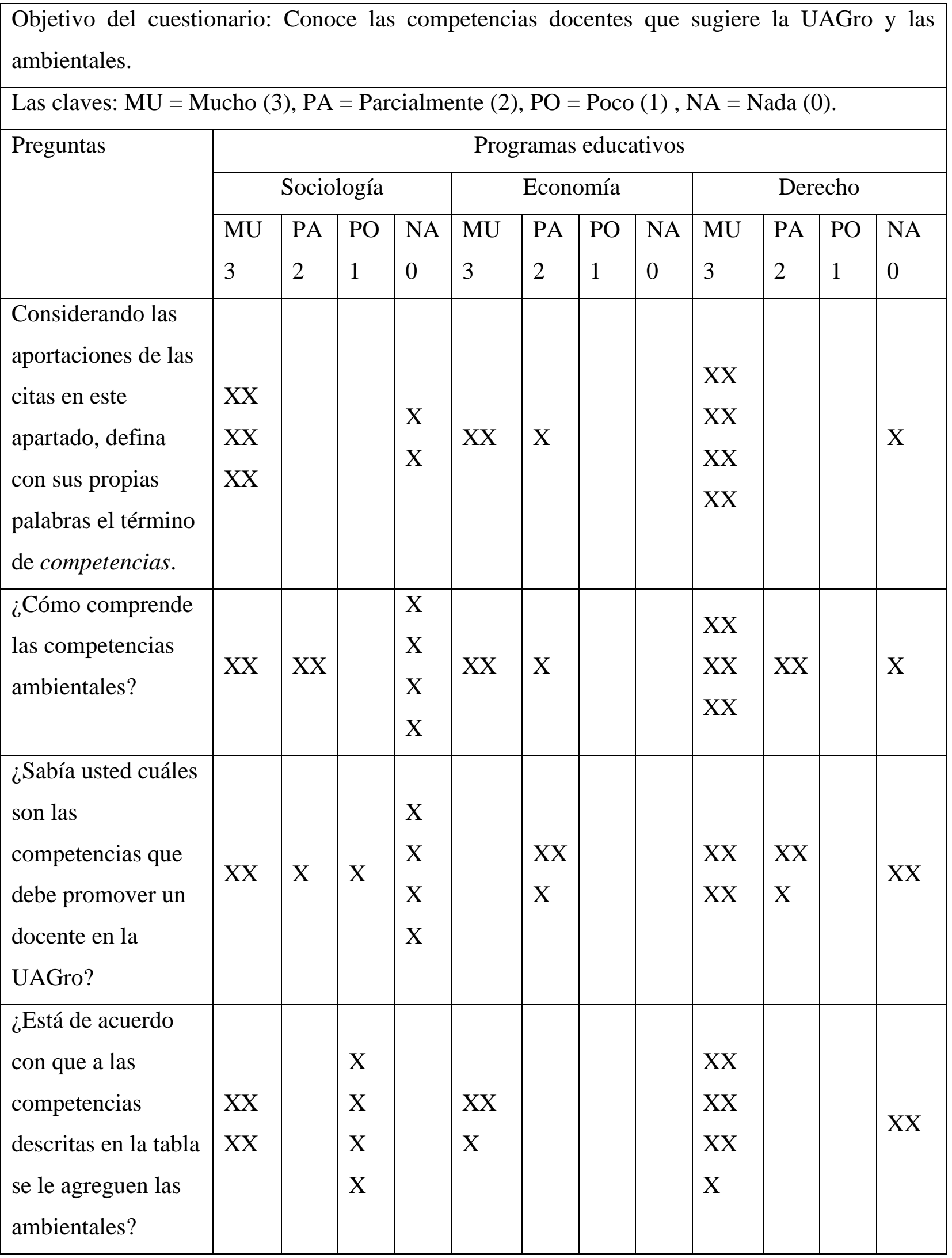




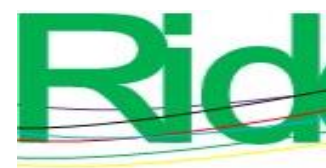

Revista Iberoamericana para la
Investigación y el Desarrollo Educativo
ISSN $2007-7467$

Fuente: Elaboración propia

En la tabla 10 se observa que son muchos los docentes que comprenden las competencias en educación y las competencias ambientales, al igual que la importancia de que un profesor en la UAGro las adquiera para aplicarlas en su labor que realiza. Sin embargo, hubo profesores de los programas de Sociología y Derecho que opinaron diferente, ello se constató en sus respuestas agrupadas en el valor NA.

\section{Octava actividad}

Los docentes leyeron el material relacionado con el tópico "Los elementos de un currículo o plan de estudio de nivel licenciatura, de un programa de unidad de aprendizaje, de una secuencia didáctica en su formato oficial y su relación con la transversalización ambiental". Luego de la lectura, respondieron un cuestionario con preguntas abiertas. El propósito de dicho instrumento fue presentar y dar a comprender a los docentes la estructura que contempla un plan de estudio, un programa de unidad de aprendizaje y una secuencia didáctica; asimismo, presentar los formatos oficiales aprobados por la UAGro para elaborarlos, sin perder de vista la metodología para introducir el elemento medio ambiente de manera transversal. (Ver tabla 11). 


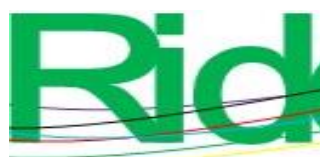

e

Revista Iberoamericana para la Investigación y el Desarrollo Educativo ISSN 2007 - 7467

Tabla 11. Resultado de la comprensión de los elementos que conforman un currículo o plan de estudio de nivel licenciatura, de un programa de unidad de aprendizaje, de una secuencia didáctica, el formato oficial UAGro en donde se plasman y su relación con la transversalización ambiental

Objetivo del cuestionario: comprende los elementos y formatos de un plan de estudio, un programa de unidad de aprendizaje y secuencia didáctica para introducir el elemento medio ambiente transversalmente.

Las claves MU = Mucho (3), PA = Parcialmente (2), PO = Poco (1), NA = Nada (0)

\begin{tabular}{|c|c|c|c|c|c|c|c|c|c|c|c|c|}
\hline \multirow[t]{3}{*}{ Preguntas } & \multicolumn{12}{|c|}{ Programas educativos } \\
\hline & \multicolumn{4}{|c|}{ Sociología } & \multicolumn{4}{|c|}{ Economía } & \multicolumn{4}{|c|}{ Derecho } \\
\hline & $\begin{array}{l}\text { MU } \\
3\end{array}$ & $\begin{array}{l}\mathrm{PA} \\
2\end{array}$ & $\begin{array}{l}\mathrm{PO} \\
1\end{array}$ & $\begin{array}{l}\text { NA } \\
0\end{array}$ & $\begin{array}{l}\text { MU } \\
3\end{array}$ & $\begin{array}{l}\text { PA } \\
2\end{array}$ & $\begin{array}{l}\text { PO } \\
1\end{array}$ & $\begin{array}{l}\text { NA } \\
0\end{array}$ & $\begin{array}{l}\text { MU } \\
3\end{array}$ & $\begin{array}{l}\text { PA } \\
2\end{array}$ & $\begin{array}{l}\mathrm{PO} \\
1\end{array}$ & $\begin{array}{l}\text { NA } \\
0\end{array}$ \\
\hline $\begin{array}{l}\text { ¿Sabes cuáles son los } \\
\text { elementos que debe } \\
\text { contemplar un currículo } \\
\text { o plan de estudio de } \\
\text { licenciatura en la } \\
\text { UAGro? Ya sea que la } \\
\text { respuesta sea afirmativa } \\
\text { o negativa, comente la } \\
\text { razón. }\end{array}$ & $X$ & $X$ & $X$ & $\begin{array}{l}X X \\
X \\
X \\
X\end{array}$ & $\mathrm{XX}$ & & & $X$ & $\begin{array}{l}X X \\
X X \\
X X\end{array}$ & XX & & $X$ \\
\hline $\begin{array}{l}\text { ¿Sabías que el diseño y } \\
\text { elaboración de un } \\
\text { currículo de licenciatura } \\
\text { debe integrar el } \\
\text { elemento medio } \\
\text { ambiente como tema } \\
\text { transversal? Ya sea que } \\
\text { la respuesta sea } \\
\text { afirmativa o negativa, } \\
\text { comente la razón. }\end{array}$ & $\mathrm{XX}$ & $X$ & & $\begin{array}{l}X X \\
X \\
X \\
X\end{array}$ & $X X$ & & & $X$ & $\begin{array}{l}X X \\
X X \\
X\end{array}$ & XX & & XX \\
\hline
\end{tabular}




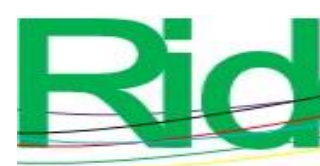

Revista Iberoamericana para la

Investigación y el Desarrollo Educativo ISSN 2007 - 7467

\begin{tabular}{|c|c|c|c|c|c|c|c|c|}
\hline $\begin{array}{l}\text { ¿Sabes cuál es el } \\
\text { formato oficial para } \\
\text { elaborar un programa } \\
\text { educativo de unidad de } \\
\text { aprendizaje o materia } \\
\text { de licenciatura en la } \\
\text { UAGro? Ya sea que la } \\
\text { respuesta sea afirmativa } \\
\text { o negativa, comente la } \\
\text { razón. }\end{array}$ & $\begin{array}{l}X X \\
X\end{array}$ & & $\begin{array}{l}X X \\
X \\
X \\
X\end{array}$ & $\mathrm{XX}$ & $X$ & & $\begin{array}{l}X X \\
X X \\
X X \\
X X\end{array}$ & $X$ \\
\hline $\begin{array}{l}\text { ¿Sabías que el diseño y } \\
\text { elaboración de un } \\
\text { programa educativo de } \\
\text { unidad de aprendizaje o } \\
\text { materia de licenciatura } \\
\text { debe integrar el } \\
\text { elemento medio } \\
\text { ambiente como tema } \\
\text { transversal? Ya sea que } \\
\text { la respuesta sea } \\
\text { afirmativa o negativa, } \\
\text { comente la razón. }\end{array}$ & $\mathrm{XX}$ & $X$ & $\begin{array}{l}X X \\
X \\
X \\
X\end{array}$ & $\mathrm{XX}$ & $X$ & & $\begin{array}{l}X X \\
X X \\
X X \\
X\end{array}$ & XX \\
\hline $\begin{array}{l}\text { ¿Sabes cuál es el } \\
\text { formato oficial para } \\
\text { elaborar una secuencia } \\
\text { didáctica o planeación } \\
\text { de actividades en el } \\
\text { nivel licenciatura en la } \\
\text { UAGro? Ya sea que la } \\
\text { respuesta sea afirmativa } \\
\text { o negativa, comente la } \\
\text { razón. }\end{array}$ & $\begin{array}{l}X X \\
X\end{array}$ & & $\begin{array}{l}X X \\
X X \\
X\end{array}$ & $X X$ & & $X$ & $\begin{array}{l}X X \\
X X \\
X X \\
X X\end{array}$ & $X$ \\
\hline
\end{tabular}




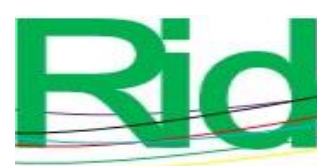

Revista Iberoamericana para la Investigación y el Desarrollo Educativo ISSN $2007-7467$

\begin{tabular}{|l|l|l|l|l|l|l|l|l|l|l|}
\hline $\begin{array}{l}\text { ¿Sabías que, en el } \\
\text { diseño y elaboración de } \\
\text { una secuencia didáctica } \\
\text { o planeación de }\end{array}$ & & & & & & & & & & \\
actividades, estas deben \\
de relacionarse con el \\
elemento medio \\
ambiente como tema \\
transversal? Ya sea que \\
$\begin{array}{l}\text { la respuesta sea } \\
\text { afirmativa o negativa, } \\
\text { comente la razón. }\end{array}$
\end{tabular}

Fuente: Elaboración propia

En la tabla 11 se observa que los profesores de los tres programas educativos comprenden y conocen qué elementos curriculares conforman un plan de estudio, un programa de unidad de aprendizaje, la secuencia didáctica y los formatos que se emplean al momento de elaborarlos. Asimismo, conocen que el medio ambiente debe permear transversalmente. Cabe aclarar también que hay profesores en los tres programas que no tenían conocimiento al respecto.

\section{Actividad nueve}

Frente a la pregunta “¿Cómo saber si la unidad de aprendizaje que imparto y que corresponde al plan de estudio de la institución donde laboro implementa el elemento medio ambiente?", los profesores realizaron una evaluación (cuali-cuantitativa) a través de una rúbrica para conocer si el programa de unidad de aprendizaje está o no ambientalizado. La dinámica de este instrumento fue que los docentes tenían que marcar los componentes del elemento medio ambiente (agua, aire, suelo, energía), traducirlos en competencias (conocimientos, habilidades, actitudes y valores) e indicar el grado en que se vinculan con el perfil de egreso o las competencias. Los resultados se presentan en la tabla 12. 


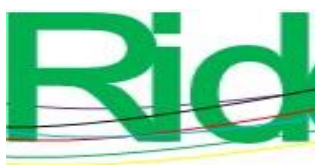

e

Revista Iberoamericana para la

Investigación y el Desarrollo Educativo

ISSN 2007 - 7467

Tabla 12. Resultado de la evaluación que se enfocó en conocer sobre el elemento medio ambiente de manera transversal en el programa de estudio que labora el profesor

Objetivo del cuestionario: identifica la dimensión ambiental con enfoque transversal en el programa de unidad de aprendizaje.

Las claves: $\mathrm{MU}=$ Mucho (3), PA = Parcialmente (2), PO = Poco (3), NA = Nada (0).

Programas educativos

\begin{tabular}{|c|c|c|c|c|c|c|c|c|c|c|c|}
\hline \multicolumn{4}{|c|}{ Sociología } & \multicolumn{4}{c|}{ Economía } & \multicolumn{4}{c|}{ Derecho } \\
\hline MU & PA & PO & NA & MU & PA & PO & NA & MU & PA & PO & NA \\
3 & 2 & 1 & 0 & 3 & 2 & 1 & 0 & 3 & 2 & 1 & 0 \\
\hline XX & $\mathrm{X}$ & $\mathrm{X}$ & $\begin{array}{c}\mathrm{XX} \\
\mathrm{XX}\end{array}$ & & $\mathrm{XX}$ & & $\mathrm{X}$ & & $\mathrm{XX}$ & $\mathrm{XX}$ & $\mathrm{XXXXX}$ \\
\hline
\end{tabular}

Fuente: Elaboración propia

En la tabla 12 se aprecia que los resultados casi fueron parejos. Hay profesores en los tres programas educativos que emplean programas de unidades de aprendizaje que incluyen el eje ambiental de manera transversal. Sin embargo, se aprecia igualmente que hay profesores en los tres programas que no implementan la dimensión ambiental.

\section{Décima actividad}

Los docentes dieron lectura y comprendieron el punto "Fundamentos pedagógicos del plan de estudio, de los programas de unidades de aprendizaje y las secuencias didácticas en la UAGro (constructivismo, aprendizaje significativo, y el enfoque de competencias en relación con el aprendizaje, rol del profesor y estudiante) y su vinculación con educación ambiental”. También aquí respondieron un cuestionario. El propósito de este apartado consistió en que los profesores comprendieran los fundamentos didácticos-pedagógicos que sustentan la práctica educativa en la UAGro. Se presenta el resultado en la tabla 13. 


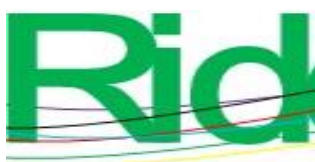

Tabla 13. Resultado de la comprensión de los fundamentos pedagógicos del plan de estudio, de los programas de unidades de aprendizaje y las secuencias didácticas en la

UAGro (constructivismo, aprendizaje significativo y el enfoque de competencias en relación con el aprendizaje, rol del profesor y estudiante) y su vinculación con la dimensión ambiental

Objetivo del cuestionario: comprende el fundamento didáctico-pedagógico de la práctica educativa en la UAGro

Las claves: $\mathrm{MU}=$ Mucho (3), PA = Parcialmente (2), PO = Poco (3), NA = Nada (0).

\begin{tabular}{|c|c|c|c|c|c|c|c|c|c|c|c|c|}
\hline \multirow[t]{3}{*}{ Preguntas } & \multicolumn{12}{|c|}{ Programas educativos } \\
\hline & \multicolumn{4}{|c|}{ Sociología } & \multicolumn{4}{|c|}{ Economía } & \multicolumn{4}{|c|}{ Derecho } \\
\hline & $\begin{array}{l}\text { MU } \\
3\end{array}$ & $\begin{array}{l}\mathrm{PA} \\
2\end{array}$ & $\begin{array}{l}\text { PO } \\
1\end{array}$ & $\begin{array}{l}\text { NA } \\
0\end{array}$ & $\begin{array}{l}\mathrm{MU} \\
3\end{array}$ & $\begin{array}{l}\mathrm{PA} \\
2\end{array}$ & $\begin{array}{l}\text { PO } \\
1\end{array}$ & $\begin{array}{l}\text { NA } \\
0\end{array}$ & $\begin{array}{l}\text { MU } \\
3\end{array}$ & $\begin{array}{l}\text { PA } \\
2\end{array}$ & $\begin{array}{l}\text { PO } \\
1\end{array}$ & $\begin{array}{l}\text { NA } \\
0\end{array}$ \\
\hline $\begin{array}{l}\text { ¿Cómo comprende el } \\
\text { enfoque pedagógico, } \\
\text { constructuvista, } \\
\text { aprendizaje significativo } \\
\text { y competencias? }\end{array}$ & $\begin{array}{l}X X \\
X\end{array}$ & $\mathrm{X}$ & & $\begin{array}{l}X \\
X \\
X \\
X\end{array}$ & $\mathrm{XX}$ & & $\mathrm{X}$ & & $\begin{array}{l}\text { XX } \\
\text { XX } \\
\text { XX }\end{array}$ & $\mathrm{XX}$ & & $X$ \\
\hline $\begin{array}{l}\text { ¿Sabías cuáles eran los } \\
\text { fundamentos } \\
\text { pedagógicos que sugiere } \\
\text { el Modelo Educativo } \\
2013 \text { de la UAGro? Ya } \\
\text { sea que la respuesta sea } \\
\text { afirmativa o negativa, } \\
\text { comente la razón. }\end{array}$ & $\begin{array}{l}X X \\
X\end{array}$ & & & $\begin{array}{l}\text { XX } \\
X \\
X \\
X\end{array}$ & $\mathrm{XX}$ & & & $X$ & $\begin{array}{l}X X \\
X\end{array}$ & $\begin{array}{l}\text { XX } \\
\text { XX }\end{array}$ & & $\mathrm{XX}$ \\
\hline $\begin{array}{l}\text { ¿El plan de estudio de la } \\
\text { institución donde labora } \\
\text { considera los } \\
\text { fundamentos } \\
\text { pedagógicos que plantea } \\
\text { el modelo educativo de la } \\
\text { universidad? Ya sea que }\end{array}$ & $\mathrm{XX}$ & & & $\begin{array}{l}\text { XX } \\
X \\
X \\
X \\
X\end{array}$ & $\mathrm{XX}$ & & $\mathrm{X}$ & & $\begin{array}{l}\text { XX } \\
\text { XX } \\
\text { XX } \\
\text { XX }\end{array}$ & & & $\mathrm{X}$ \\
\hline
\end{tabular}




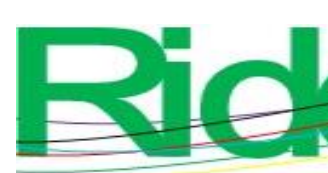

Revista Iberoamericana para la Investigación y el Desarrollo Educativo ISSN 2007 - 7467

afirmativa o negativa, comente la razón.

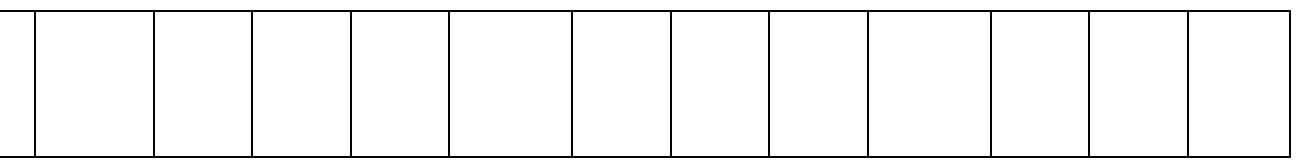

Fuente: Elaboración propia

En la tabla 13 se observa que los profesores de los tres programas educativos comprenden los enfoques pedagógicos-didácticos de su práctica docente y es fundamento de planes de estudios, de programas de unidades de aprendizajes y secuencias didácticas; comprenden también que estos enfoques permearían la inclusión de la educación ambiental como tema transversal. Finalmente, hay profesores cuyas respuestas fueron ubicadas en NA.

\section{Décima primera actividad}

Los docentes dieron lectura y comprendieron el punto "Estrategias y técnicas didácticas en educación ambiental". Aunado a ello, elaboraron una estrategia y técnica didáctica sobre un contenido a desarrollar. El propósito de este apartado consistió en que los profesores comprendieran cómo diseñar estrategias que incorporen un método, una estrategia educativa, técnica didáctica, actividades y recursos para desarrollar un tema apegado al programa de su materia y vinculado este a lo ambiental. (Ver tabla 14).

Tabla 14. Resultado de la elaboración de una estrategia y técnica didáctica en educación ambiental sobre un contenido de su programa de unidades de aprendizaje

\begin{tabular}{|c|c|c|c|c|c|c|c|c|c|c|c|}
\hline \multicolumn{12}{|c|}{$\begin{array}{l}\text { Objetivo: comprende } 1 \\
\text { educación ambiental. }\end{array}$} \\
\hline \multicolumn{12}{|c|}{ Las claves: $\mathrm{MU}=$ Mucho (3), PA = Parcialmente (2), PO = Poco (3), NA = Nada (0). } \\
\hline \multicolumn{12}{|c|}{ Programas educativos } \\
\hline \multicolumn{4}{|c|}{ Sociología } & \multicolumn{4}{|c|}{ Economía } & \multicolumn{4}{|c|}{ Derecho } \\
\hline MU & $\mathrm{PA}$ & PO & NA & MU & $\mathrm{PA}$ & PO & $\mathrm{NA}$ & MU & $\mathrm{PA}$ & PO & $\mathrm{NA}$ \\
\hline 3 & 2 & 1 & 0 & 3 & 2 & 1 & 0 & 3 & 2 & 1 & 0 \\
\hline $\begin{array}{l}\mathrm{XX} \\
\mathrm{XX}\end{array}$ & & & $\begin{array}{l}X X \\
X X\end{array}$ & XX & & & X & $\begin{array}{c}\text { XX } \\
\text { XX } \\
\text { X }\end{array}$ & & & XX X X \\
\hline
\end{tabular}

Fuente: Elaboración propia 


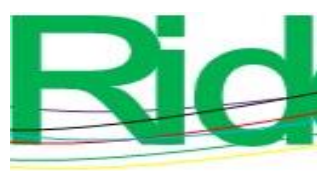

e

Revista Iberoamericana para la Investigación y el Desarrollo Educativo

ISSN 2007 - 7467

En la tabla 14 se constata que, con ayuda del material didáctico, algunos docentes lograron elaborar una estrategia y emplear una técnica apegada a la dimensión ambiental con enfoque transversal y vincularla con la unidad de aprendizaje o materia que trabaja, aunque también se observa que hubo profesores que no realizaron la actividad.

\section{Evaluación de las actividades del segundo capítulo de la guía didáctica}

Para evaluar los resultados de las actividades del segundo capítulo de la guía o material didáctico, se contempló la metodología que se empleó en el capítulo uno.

\section{Primera actividad del capítulo dos}

Los docentes analizaron de manera práctica el apartado "Currículo o plan de estudio ambientalizado y con escasa ambientalización”. Luego realizaron una actividad que consistió en la identificación de dos currículos o planes de estudio, uno ambientalizado y el otro sin ambientalizar. El propósito fue que los docentes distinguieran simbólicamente currículos que incluyen y que no incluyen la dimensión ambiental. Los resultados se aprecian en la tabla 15.

Tabla 15. Resultado de la actividad "Distingue un currículo o plan de estudio ambientalizado y con escasa ambientalización"

\begin{tabular}{|c|c|c|c|c|c|c|c|c|c|c|c|}
\hline $\begin{array}{l}\text { Objet } \\
\text { ambi }\end{array}$ & $\begin{array}{l}\mathrm{O}: \\
\text { taliz }\end{array}$ & $\begin{array}{l}\text { ting } \\
\text { ón. }\end{array}$ & un & Irrícul & $\mathrm{amb}$ & tali & ado & $y \quad \sin$ & mbie & $\mathrm{O}$ & esca \\
\hline Las c & ves: & $\mathrm{U}=\mathrm{I}$ & cho ( & $\mathrm{PA}=$ & cial & ente & (2), $\mathrm{P}$ & $=\mathrm{P}$ & (3), $N$ & ada & \\
\hline & & & & & rogra & nas e & lucati & & & & \\
\hline & Soc & ogía & & & cono & & & & & cho & \\
\hline MU & PA & PO & NA & MU & PA & $\mathrm{PO}$ & NA & MU & PA & PO & NA \\
\hline 3 & 2 & 1 & 0 & 3 & 2 & 1 & 0 & 3 & 2 & 1 & 0 \\
\hline XX & & & $\begin{array}{l}\text { X X } \\
\text { X X } \\
\text { X X }\end{array}$ & XX & & & $X$ & $\begin{array}{c}\text { XX } \\
\text { XX } \\
\text { XX } \\
\text { X }\end{array}$ & & & X X \\
\hline
\end{tabular}

Fuente: Elaboración propia 


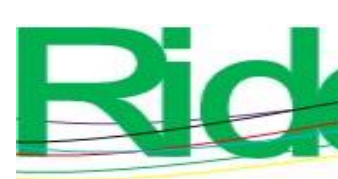

\section{Revista Iberoamericana para la Investigación y el Desarrollo Educativo ISSN 2007 - 7467}

competencias adquiridas sobre la inclusión de la educación o dimensión ambiental en un programa de unidad de aprendizaje.

\section{Cuarta actividad del capítulo dos}

Los docentes analizaron de manera práctica el apartado "Ambientaliza tu secuencia didáctica (implementa el elemento ambiental en los elementos de la secuencia didáctica)” y realizaron una actividad que consistió en revisar los elementos que conforman la planeación o secuencia didáctica. La finalidad de este ejercicio fue que se introdujera el elemento medio ambiente en una sesión o una clase. Para hacer esta actividad, la guía contó con ejemplos. El propósito fue que los docentes ambientalizaran al menos una sesión o clase para que se dieran cuenta de cómo vincular actividades que son propias de la materia que les toca impartir con aspectos socioambientales. Se aprecian los resultados en la tabla 18.

Tabla 18. Resultado de la actividad "Ambientaliza tu secuencia didáctica (implementa el elemento ambiental en los elementos de la secuencia didáctica)"

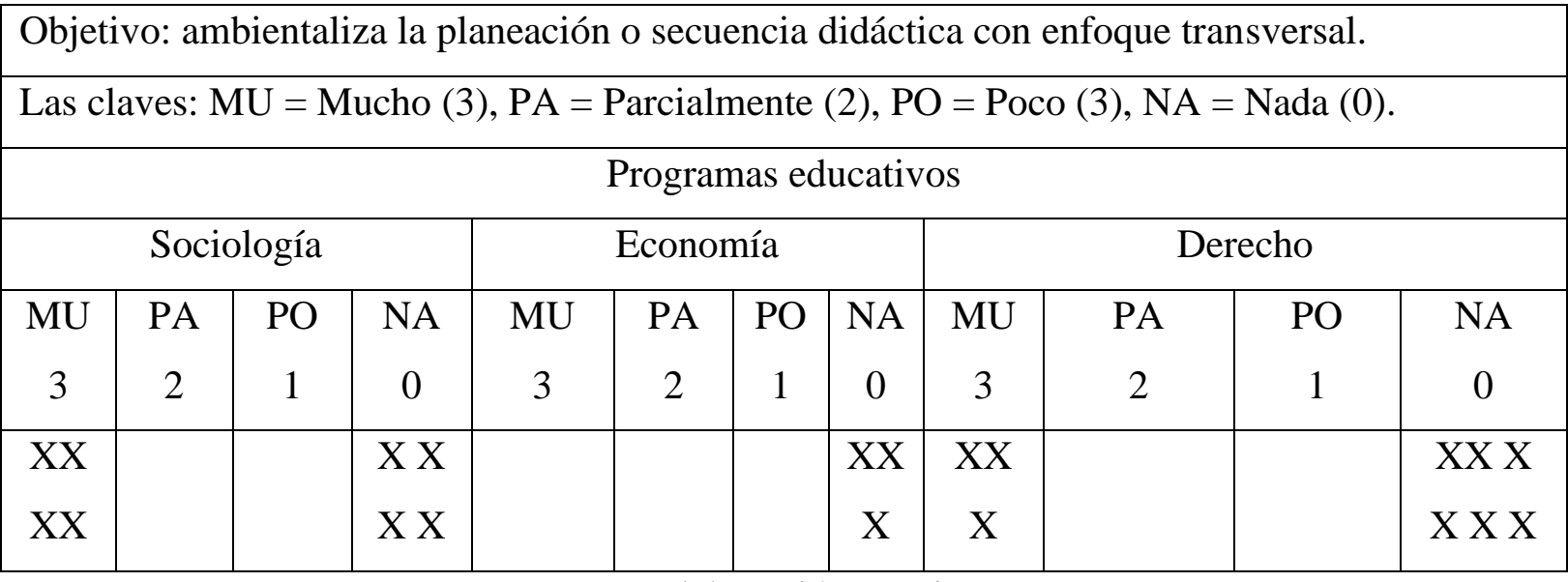

Fuente: Elaboración propia

En la tabla 18 se observa que en los programas de estudio de Derecho y Sociología fueron menos docentes los que realizaron la actividad y más los que no la realizaron. Sin embargo, los que realizaron esta tarea se dieron cuenta de cómo incluir la dimensión ambiental transversalmente en el diseño de su secuencia didáctica. Así, se percibió que ambientalizaron una sesión de una de sus secuencias didácticas. 


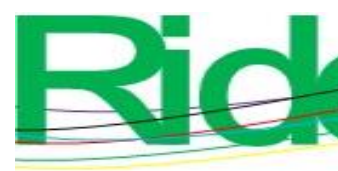

Revista Iberoamericana para la
Investigación y el Desarrollo Educativo
ISSN $2007-7467$

aprendizaje en la que laboran; muy pocos dicen que un poco. Finalmente, casi todos afirman no contar con competencias ambientales y, por consiguiente, estrategias de educación ambiental en su práctica educativa.

Ahora bien, la mayoría de los docentes entrevistados de Sociología comprendió que el modelo educativo de la UAGro establece, en sus principios y ejes transversales, el elemento medio ambiente para implementarse transversalmente y casi todos están de acuerdo con que este incluya la educación ambiental en el plan de estudio donde laboran. De igual manera, casi todos comprendieron que el modelo educativo hace referencia a que la dimensión ambiental en el currículo debe ser transversalmente. En Economía, casi todos los entrevistados comprendieron que la inclusión de lo ambiental de forma transversal coadyuva a la sustentabilidad que nuestro mundo requiere. En Derecho, casi todos los docentes comprendieron que el modelo educativo de la UAGro establece en sus principios y ejes transversales el elemento medio ambiente para implementarse transversalmente; también casi todos están de acuerdo con que el elemento medio ambiente incluya la educación ambiental transversalmente en el plan de estudio donde laboran.

Los entrevistados de Sociología, Economía y Derecho perciben, en su mayoría, la problemática como un tema preocupante, y todos están de acuerdo en que los seres humanos son los responsables de esta crisis; casi todos percibieron que un problema de esta índole no solo repercute en una zona, sino que se extiende a otras, y todos están de acuerdo en que la crisis ambiental se refleja en lo social, cultural, económico y en otros aspectos de la sociedad.

Los docentes entrevistados de la licenciatura de Sociología, casi todos, comprendieron que entre los años 80 la educación ambiental se enfocaba en atender problemas de la naturaleza solamente. En este mismo tenor, casi todos comprendieron que después de los 90 esta educación comenzó a comprenderse como un proceso que vincula lo ambiental con lo social, lo económico y lo cultural. También que, si se implementa en el currículo, esta debe ser incluida como parte de un proceso y no como una materia. Y casi todos comprendieron que esta educación debe integrarse al currículo con un enfoque ambientalista porque es más integrador. Los docentes de Economía y Derecho dieron la misma respuesta.

En lo concerniente al desarrollo sustentable, casi todos los docentes entrevistados de los tres programas educativos hicieron alusión a que la sustentabilidad implica implementar la educación ambiental porque si se cuenta con un medio ambiente sano se contribuye a un equilibrio social y económico. 


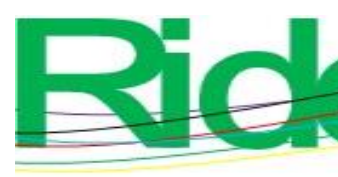

Revista Iberoamericana para la Investigación y el Desarrollo Educativo ISSN $2007-7467$

Fueron muy pocos docentes en Sociología que comprendieron a la educación ambiental como un tema transversal en el currículo, al igual que la metodología para ser incorporada en el plan de estudio. Sin embargo, casi más de la mitad entendió cómo se incorpora en el programa de unidad de aprendizaje. Casi todos los docentes de Economía que realizaron esta actividad visualizaron a la educación ambiental como un tema transversal en el currículo. Casi todos los docentes de Derecho que realizaron esta actividad comprendieron a la educación ambiental como tema transversal en el currículo y descubrieron cómo esta puede ser introducida transversalmente en el currículo o plan de estudio y en la unidad de aprendizaje.

Todos los docentes entrevistados en Sociología comprendieron qué son las competencias, sin embargo, hay deficiencias en algunos en comprender qué son las competencias ambientales. Son muy pocos los que conocen que en la UAGro hay competencias descritas para docentes de nivel licenciatura. Todos están de acuerdo en que entre las competencias que se han descrito en la UAGro para sus docentes incluyan a las ambientales, debido a que no se mencionan como tal. Casi todos los docentes de Economía comprenden qué son las competencias y por extensión comprenden las competencias ambientales. Todos comprenden cuáles son las competencias docentes descritas en la UAGro y todos están de acuerdo en que las competencias ambientales sean anexadas. Todos los docentes en Derecho comprenden qué son las competencias de manera general, sin embargo, la mayoría comprende poco de las competencias que se enfocan en lo ambiental. Menos de la mitad sabía cuáles eran las competencias que la UAGro tenía descritas para sus docentes y la mayoría que las competencias ambientales deben ser consideradas como otra competencia docente por la urgencia del tema.

Fueron muy pocos los docentes de Sociología que conocían los elementos para elaborar un plan de estudio; igualmente, muy pocos sabían que un plan de estudio en la UAGro debe estar ambientalizado. La mitad de los docentes conocían el formato para elaborar un programa de unidad de aprendizaje. Muy pocos sabían que un programa de unidad de aprendizaje y la secuencia didáctica deben estar ambientalizados o implementar el elemento ambiental transversalmente, sin embargo, a partir de la información esta falencia fue parcialmente solventada. La mayoría de los docentes de economía conocen los elementos que contempla un plan de estudio de licenciatura en la UAGro. De igual manera, que un plan de estudio en la UAGro debe estar ambientalizado. Conocían el formato para elaborar un programa de unidad de aprendizaje y sabían que un programa de unidad de aprendizaje y la 


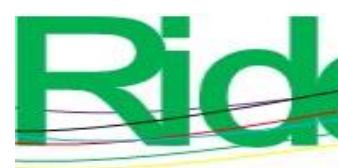

Revista Iberoamericana para la Investigación y el Desarrollo Educativo ISSN 2007 - 7467

secuencia didáctica deben estar ambientalizados o implementar el elemento ambiental transversalmente. Esto refleja que la mayoría comprende ahora que dicho elemento debe permear en el currículo (plan de estudio, programa de unidad de aprendizaje y secuencia didáctica). La mayoría de los docentes de Derecho conocen los elementos que contempla un plan de estudio de licenciatura en la UAGro. También sabían que un plan de estudio en la UAGro debe estar ambientalizado. Conocían el formato para elaborar un programa de unidad de aprendizaje y sabían que un programa de unidad de aprendizaje y la secuencia didáctica debe estar ambientalizados o implementar el elemento ambiental transversalmente. Esta actividad reforzó los aprendizajes para que la mayoría de los docentes comprenda ahora que dicho elemento debe permear en el currículo (plan de estudio, programa de unidad de aprendizaje y secuencia didáctica).

Algunos docentes de la unidad académica de Sociología se dieron cuenta de que el programa de la unidad de aprendizaje que laboran no está completamente ambientalizado. La mayoría de los docentes de Economía identificó que sus programas de unidades de aprendizaje están parcialmente vinculados con elementos ambientales. Docentes de Derecho comprendieron que los programas de unidades de aprendizaje están parcialmente y poco vinculado con el ambiente.

La mitad de los docentes de Sociología comprenden ahora los enfoques pedagógicos (constructivismo, aprendizaje significativo y competencias) que sugiere el modelo educativo de la UAGro; sin embargo, muy pocos constatan que el plan de la institución no comprende dichos enfoques. Muy pocos comentan también que las actividades que se realizan en el aula no integran los enfoques sugeridos. Casi todos comprendieron la necesidad de la introducción de la educación ambiental en el currículo bajo dichos enfoques. La mitad de los docentes de Economía comprende ahora los enfoques pedagógicos (constructivismo, aprendizaje significativo y competencias) que sugiere el modelo educativo de la UAGro, sin embargo, la mitad expresa que el plan de la institución no comprende dichos enfoques. La mitad comenta también que las actividades que se realizan en el aula no integran los enfoques sugeridos. Casi todos comprendieron la necesidad de la introducción de la educación ambiental en el currículo bajo dichos enfoques. Casi todos los docentes de Derecho comprenden ahora los enfoques pedagógicos (constructivismo, aprendizaje significativo y competencias) que sugiere el modelo educativo de la UAGro, casi todos expresan también que el plan de la institución no comprende dichos enfoques. Casi todos comentan también que las actividades 


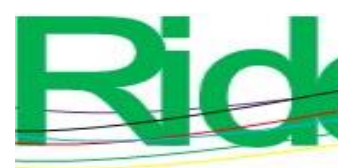

Revista Iberoamericana para la Investigación y el Desarrollo Educativo ISSN $2007-7467$

que se realizan en el aula no integran los enfoques sugeridos. Casi todos comprendieron la necesidad de la introducción de la educación ambiental en el currículo bajo dichos enfoques.

Casi todos los docentes de Sociología comprendieron la elaboración de una estrategia didáctica que integra la educación ambiental transversalmente; en Economía y Derecho fue el mismo caso. En lo concerniente a la actividad en donde identificaron un currículo ambientalizado y uno que no lo está, casi todos los docentes entrevistados en los tres programas que realizaron esta actividad se dieron cuenta de lo que es un currículo ambientalizado y uno que no lo está.

Algunos docentes de Sociología vincularon el elemento ambiental con el perfil de egreso del plan de estudio. Aunado a ello, comprendieron que el elemento medio ambiente tiene que ir implícito transversalmente en el plan de estudio de la institución. Los docentes de la unidad académica de Economía relacionaron el eje medio ambiente con el perfil de egreso también. En Derecho también algunos docentes elaboraron la actividad y comprendieron que el elemento medio ambiente tiene que ir implícito transversalmente en el plan de estudio de la institución.

Los docentes de la unidad académica de Sociología realizaron y comprendieron la actividad de cómo debe implementarse el elemento ambiental transversalmente en un programa de unidad de aprendizaje. Los docentes de la unidad académica de Economía que realizaron esta actividad comprenden ahora cómo debe implementarse el elemento ambiental transversalmente en un programa de unidad de aprendizaje, también los docentes de la unidad académica de Derecho que realizaron esta actividad comprendieron cómo debe implementarse el elemento ambiental transversalmente en un programa de unidad de aprendizaje.

Los docentes de la unidad académica los tres programas realizaron una actividad sobre cómo debe implementarse el elemento ambiental transversalmente en una secuencia didáctica. Al revisar la actividad se visualizaron excelentes resultados.

A través de la evaluación realizada, se identificó que los profesores de los tres programas que participaron lograron comprender información importante en relación con aspectos pedagógicos y de educación ambiental para que implementen lo adquirido en el currículo y en las tareas que les toca llevar a cabo en la universidad.

Los resultados de este estudio coinciden con estrategias que se han diseñado con base en programas educativos y cursos-talleres sobre la integración de la dimensión ambiental en planes, programas de estudio, secuencias didácticas y la formación ambiental de los docentes 


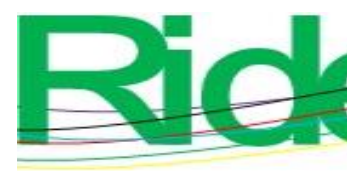

Revista Iberoamericana para la Investigación y el Desarrollo Educativo ISSN 2007 - 7467

como, por ejemplo. El estudio realizado por de Souza, Bueno, Duarte y Da Silva (2015) expusieron que los resultados de un curso que tuvo como objetivo promover la formación pedagógica en educación ambiental realizado con diecisiete estudiantes en el año 2014 de una universidad pública del Estado de Paraná (Brasil), todos graduados y trabajaban como docentes, concluyó que el curso trajo contribuciones a los participantes que mostraron, entre otras cosas, una mejoría en la comprensión de los asuntos abordados en una postura más clara frente a sus acciones diarias y la perspectiva ambiental. Asimismo, Súcar (2003) menciona que el Programa Institucional de Medio Ambiente, en la Universidad de Guanajuato (Pimaug), en febrero de 2001, tuvo como uno de sus objetivos la incorporación de la dimensión ambiental en los planes y programas educativos del nivel medio superior y superior. Las primeras de las acciones formales realizadas con el fin de iniciar un proceso de "ambientalización" como parte fundamental de formación universitaria fue un curso-taller en donde asistieron 20 profesores y profesoras. La realización de este evento permitió una sensibilización, y despertó un interés genuino en los asistentes, quienes iniciaron un análisis propio de sus actividades docentes y de la manera en que podrían incorporar la dimensión ambiental. En relación con el curso-taller, también los profesores y profesoras expusieron distintas percepciones que tenían sobre la situación ambiental y sobre las implicaciones de la incorporación de esta dimensión en cursos de distintas áreas de conocimiento.

Otro estudio que se enfoca en la formación docente en saberes ambientales es el que presentaron Miranda, Bedolla y Sampedro (2020). Se trata de una investigación que se desarrolló en 2017 en la Unidad Académica de Ciencias y Tecnologías de la Información (UACyTI), dependiente de la UAGro, en la ciudad de Acapulco, Guerrero, México, que tuvo como propósito la transversalización del eje medio ambiente en el nivel superior. Una de sus etapas planteó una propuesta de formación docente en saberes ambientales, diseño curricular y transversalización. Consecuentemente, se diseñó y aplicó un curso-taller que promovió nuevos conocimientos en materia ambiental en los docentes; también se dio a conocer una metodología para integrar contenidos relacionados con la transversalidad del eje medio ambiente en el programa y la secuencia didáctica necesarios para desarrollar competencias ambientales en los estudiantes.

Con los estudios presentados en párrafos anteriores se constata que tanto en México como en otras partes del mundo se recurre a la "estrategia" del diseño y aplicación de programas o cursos-talleres cuando se pretende formar ambientalmente al profesorado.

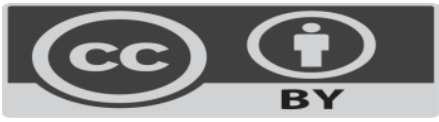




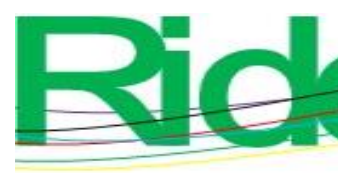

Revista Iberoamericana para la Investigación y el Desarrollo Educativo ISSN $2007-7467$

\section{Conclusiones}

El método aplicado para desarrollar competencias ambientales con los docentes de los tres programas de estudios que se mencionan en el contenido de este trabajo dio resultados favorables ya que logró dar a conocer, comprender y promover habilidades relacionadas con la dimensión ambiental. Asimismo, permitió formar una visión prospectiva por el hecho de dar orientaciones de cómo aplicarla en las actividades escolares que realiza, esto se constató en la evaluación de las actividades y por ende, las evidencias entregadas. Los profesores son los actores principales del proceso educativo y por esta razón, es fundamental que conozcan los lineamientos o directrices curriculares en cuanto a lo que contempla o integra el currículo de la institución donde labora. En este caso, la dimensión ambiental, por ser la problemática ambiental un tema emergente y preocupante, se ha integrado de manera responsable en el currículo de la universidad. Y así, a través de la universidad. se coadyuve en la sustentabilidad que el mundo requiere. Esto se logrará siempre y cuando se cuide y deje de afectar el medio ambiente.

Los profesores son una pieza clave en la universidad. Es importante que cuenten con competencias ambientales para ponerlas en marcha en las actividades o los quehaceres educativos que llevan a cabo. Un profesor debe conocer su plan de estudios, saber cuáles son los temas transversales que deben llevarse a cabo, debe conocer ambientalizar su programa de estudio o de la materia que trabaja y cómo integrar la dimensión ambiental en la secuencia didáctica, al igual que aplicar estrategias, diseñar evidencias, evaluar aprendizajes apegados al eje medio ambiente con un enfoque transversal. Las universidades, en algunos casos, integran algunos proyectos o temas transversales en el currículo; sin embargo, no se capacita al docente sobre su aplicación, por ello los docentes reflejan esa falta de conocimientos sobre cómo implementar lo que se encomienda. Lo que se expone en este trabajo proyecta la necesidad actual de continuar en la gestión de la dimensión ambiental (transversal) en el currículo y en la formación ambiental de los profesores para que tribute en el trabajo que llevan a cabo y con ello coadyuvar en la sustentabilidad que el mundo requiere. 


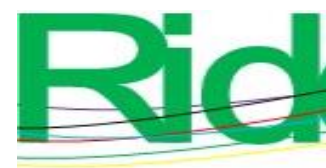

Revista Iberoamericana para la
Investigación y el Desarrollo Educativo
ISSN $2007-7467$

Futuras líneas de investigación

Este estudio se enmarca en el campo educativo, las ciencias ambientales y en las líneas de investigación de la educación ambiental para la sustentabilidad. Es referente teórico para estudios o investigaciones que se realicen dentro del campo educativo y las ciencias ambientales. Se enfoca en el papel que desempeña el docente en el trabajo que le toca realizar, considerando los enfoques teóricos y metodológicos, pedagógicos y didácticos como el enfoque de competencias y el constructivismo social. Por este hecho, la inclusión de la dimensión ambiental con enfoque transversal no solo permea el currículo, programas de unidades de aprendizaje y la secuencia didáctica, sino las competencias ambientales del profesor que son necesarias para su desempeño. Los planes de estudio de universidades en todo el mundo están obligados a incluir la dimensión ambiental transversalmente porque la problemática ambiental y socioambiental aqueja a todos por igual. En este orden de ideas, un currículo debe incorporar las exigencias del contexto. La ambientalización curricular, entonces, comprende varios aspectos a reconsiderar en la tarea curricular; una de ellas es la actualización de sus profesores, debido a que deben de estar preparados con las competencias ambientales necesarias para aplicar estrategias y técnicas de aprendizaje en el trabajo que realizan. Así, esas competencias tributarán en la formación de competencias ambientales y transversales en los estudiantes para enfrentar los retos de esta índole en el presente y en el futuro. 


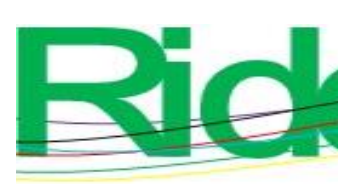

Revista Iberoamericana para la
Investigación y el Desarrollo Educativo
ISSN $2007-7467$

Miranda, E. A., Bedolla, S. R. y Sampedro, R. M.L. (2020). Formación docente para integrar el eje medio ambiente en el proceso de enseñanza-aprendizaje en el nivel superior en la universidad autónoma de Guerrero México. Revista Pedagógica, Chapecó, 22, 113.

Moscoso, J. (2017). Los métodos mixtos en la investigación en educación: Hacia un uso reflexivo. Cadernos de Persquisa, 47(16), 632-649.

Organización de las Naciones Unidas para la Educación, la Ciencia y la Cultura [Unesco]. (s. f.). ¿Qué hace la Unesco en relación con la educación para el desarrollo sostenible? Recuperado de https://es.unesco.org/themes/educacion-desarrollosostenible/acciones-unesco.

Osses B. Sonia, Sánchez t. Ingrid; Ibáñez F. Flor (2006). Investigación cualitativa en educación. Hacia la generación de teoría a través del proceso analítico. Estudios pedagógicos, 32 (1), 119-133.

Quiroz, B. I., S. Del Amo R., y J. M. Ramos, P. (2011). Desarrollo sustentable, ¿discurso político o necesidad urgente? La Ciencia y el Hombre, 34(3), 11-16.

Serrano, J. M., y Pons, R. M. (2011). El constructivismo hoy: enfoques constructivistas en educación. Revista Electrónica de Investigación Educativa, 13(1), 1-27.

Súcar, S. S. (2003). La formación de los profesores: proceso fundamental para una educación ambiental. La experiencia de la Universidad de Guanajuato. Programa Institucional de Medio Ambiente de la Universidad de Guanajuato, PIMAUG. Ponencia presentada en el Primer Foro Nacional sobre la Incorporación de la Perspectiva Ambiental en la Formación Técnica y Profesional. San Luis Potosí, del 9 al 13 de junio de 2003.

Universidad Autónoma de Guerrero [UAGro]. (2004). Modelo Educativo y Académico 2004. Chilpancingo, México: Universidad Autónoma de Guerrero.

Universidad Autónoma de Guerrero [UAGro]. (2013). Modelo Educativo. Hacia una educación de calidad con inclusión social. Chilpancingo, México: Universidad Autónoma de Guerrero.

Universidad Autónoma de Guerrero [UAGro]. (2014). Anuario Estadístico 2013-2014. Chilpancingo, Guerrero: Universidad Autónoma de Guerrero. 


\begin{tabular}{|c|c|}
\hline Rol de Contribución & Autor(es) \\
\hline Conceptualización & $\begin{array}{l}\text { Ramón Bedolla Solano, Adriana Miranda Esteban, Juan Jose } \\
\text { Bedolla Solano }\end{array}$ \\
\hline Metodología & $\begin{array}{l}\text { Ramón Bedolla Solano, Adriana Miranda Esteban, Juan Jose } \\
\text { Bedolla Solano }\end{array}$ \\
\hline Software & Juan Jose Bedolla Solano \\
\hline Validación & Ramón Bedolla Solano, Adriana Miranda Esteban \\
\hline Análisis formal & $\begin{array}{l}\text { Ramón Bedolla Solano, Adriana Miranda Esteban, Juan Jose } \\
\text { Bedolla Solano }\end{array}$ \\
\hline Investigación & $\begin{array}{l}\text { Ramón Bedolla Solano, Adriana Miranda Esteban, Juan Jose } \\
\text { Bedolla Solano }\end{array}$ \\
\hline Recursos & $\begin{array}{l}\text { Ramón Bedolla Solano, Adriana Miranda Esteban, Juan Jose } \\
\text { Bedolla Solano }\end{array}$ \\
\hline Curación de datos & Ramón Bedolla, Adriana Miranda Esteban \\
\hline $\begin{array}{l}\text { Escritura. Preparación del } \\
\text { borrador original }\end{array}$ & Ramón Bedolla, Adriana Miranda Esteban \\
\hline Escritura. Revisión y edición & Ramón Bedolla, Adriana Miranda Esteban \\
\hline Visualización & Juan José Bedolla Solano, Adriana Miranda Esteban \\
\hline Supervisión & Ramón Bedolla Solano, Adriana Miranda Esteban \\
\hline Administración de proyectos & Ramón Bedolla Solano \\
\hline Adquisición de fondos & Ramón Bedolla Solano \\
\hline
\end{tabular}

